\title{
Advanced exergy analysis of a Joule-Brayton pumped thermal electricity storage system with liquid-phase storage
}

\author{
Yongliang Zhao ${ }^{1,2}$, Ming Liu ${ }^{1}$, Jian Song ${ }^{2}$, Chaoyang Wang ${ }^{1}$, Junjie Yan ${ }^{1, *}$ and Christos N. Markides ${ }^{2, *}$ \\ ${ }^{1}$ State Key Laboratory of Multiphase Flow in Power Engineering, Xi'an Jiaotong University, Xi'an 710049, China \\ ${ }^{2}$ Clean Energy Processes (CEP) Laboratory and Centre for Process Systems Engineering (CPSE), \\ Department of Chemical Engineering, Imperial College London, London SW7 2AZ, UK \\ *Corresponding authors: yanij@mail.xitu.edu.cn; c.markides@imperial.ac.uk
}

\begin{abstract}
N.B.: This is the ACCEPTED MANUSCRIPT version of this article. The final, published version of the article can be found at: https://doi.org/10.1016/j.enconman.2021.113867.
\end{abstract}

\begin{abstract}
Pumped thermal electricity storage is a thermo-mechanical energy storage technology that has emerged as a promising option for large-scale (grid) storage because of its lack of geographical restrictions and relatively low capital costs. This paper focuses on a $10 \mathrm{MW}$ Joule-Brayton pumped thermal electricity storage system with liquid thermal stores and performs detailed conventional and advanced exergy analyses of this system. Results of the conventional exergy analysis on the recuperated system indicate that the expander during discharge is associated with the maximum exergy destruction rate (13\%). The advanced exergy analysis further reveals that, amongst the system components studied, the cold heat exchanger during discharge is associated with the highest share $(95 \%)$ of the avoidable exergy destruction rate, while during charge the same component is associated with the highest share (64\%) of the endogenous exergy destruction rate. Thus, the cold heat exchanger offers the largest potential for improvement in the overall system exergetic efficiency. A quantitative analysis of the overall system performance improvement potential of the recuperated system demonstrates that increasing the isentropic efficiency of the compressor and turbine from $85 \%$ to $95 \%$ significantly increases the modified overall exergetic efficiency from $37 \%$ to $57 \%$. Similarly, by increasing the effectiveness and decreasing the pressure loss factor of all heat exchangers, from 0.90 to 0.98 and from $2.5 \%$ to $0.5 \%$ respectively, the modified overall exergetic efficiency increases from $34 \%$ to $54 \%$. The results of exergy analyses provide novel insight into the innovation, research and development of pumped thermal electricity storage technology.
\end{abstract}

Keywords: advanced exergy analysis; Joule-Brayton cycle; energy storage; pumped thermal electricity storage; PTES; sensible heat thermal storage.

\section{Nomenclature}

\begin{tabular}{llll}
\multicolumn{2}{l}{ Symbols } & \\
$E$ & Internal energy [W] & EES & Electrical energy storage \\
$E_{\mathrm{D}, k}$ & Exergy destruction rate of the kth component [W] & EXP & Expander \\
$E_{\mathrm{F}, k}$ & Fuel exergy rate of the $k$ th component $[\mathrm{W}]$ & $\mathrm{HE}$ & Heat engine \\
$E_{\mathrm{P}, k}$ & Product exergy rate of the $k$ th component $[\mathrm{W}]$ & $\mathrm{HHX}$ & Hot heat exchanger \\
$E_{\mathrm{x}}$ & Exergy [W] & $\mathrm{HP}$ & Heat pump \\
$\mathrm{Q}$ & Heat transfer rates [W] & LAES & Liquid air energy storage
\end{tabular}




\begin{tabular}{|c|c|c|c|}
\hline$T$ & Temperature $[\mathrm{K}]$ & LCOS & Levelised cost of storage \\
\hline$c_{p}$ & Specific heat capacity $[\mathrm{J} /(\mathrm{kg} \cdot \mathrm{K})]$ & ORC & Organic Rankine cycle \\
\hline$e_{x}$ & Specific exergy $[\mathrm{J} / \mathrm{kg}]$ & PTES & $\begin{array}{l}\text { Pumped thermal electricity } \\
\text { storage }\end{array}$ \\
\hline$f_{\mathrm{p}}$ & Pressure loss factor [\%] & $\mathrm{RCT}$ & Recuperator \\
\hline$h$ & Specific enthalpy $[\mathrm{J} / \mathrm{kg}]$ & RES & Renewable energy source \\
\hline$k$ & Thermal conductivity $[\mathrm{W} /(\mathrm{m} \cdot \mathrm{K})]$ & SC-CCES & $\begin{array}{l}\text { Supercritical compressed } \mathrm{CO}_{2} \\
\text { energy storage }\end{array}$ \\
\hline$\dot{m}$ & Mass flow rate $[\mathrm{kg} / \mathrm{s}]$ & & \\
\hline$p$ & Pressure $[\mathrm{Pa}]$ & Subscripts & \\
\hline$\Delta p$ & Pressure drop [Pa] & SCK & Storage tank \\
\hline$s$ & Specific entropy $[\mathrm{J} /(\mathrm{kg} \cdot \mathrm{K})]$ & actual & Actual value \\
\hline$w$ & Specific power [W] & c & Cold stream \\
\hline$y_{\mathrm{D}, k}$ & Exergy destruction ratio of the $k$ th component [-] & $\mathrm{h}$ & Hot stream \\
\hline$y_{\mathrm{D}, k}^{\prime}$ & Relative exergy destruction of the $k$ th component [\%] & in & Inflow \\
\hline$\beta$ & Pressure ratio $[-]$ & is & Isentropic process \\
\hline$\varepsilon$ & Effectiveness of a heat exchanger [-] & $\max$ & Maximum value \\
\hline$\eta$ & Isentropic efficiency [\%] & $\min$ & Minimum value \\
\hline$\kappa$ & Insulation factor [\%] & out & Outflow \\
\hline$\mu$ & Viscosity [Pa.s] & pinch & Pinch point \\
\hline$\rho$ & Density $\left[\mathrm{kg} / \mathrm{m}^{3}\right]$ & $\mathrm{s}$ & Storage liquid \\
\hline$\phi_{k}$ & Initial exergetic efficiency of the $k$ th component [\%] & tank & Tanks \\
\hline$\phi_{k}^{\prime}$ & $\begin{array}{l}\text { Modified exergetic efficiency of the } k \text { th component } \\
\text { [\%] }\end{array}$ & tot & Total \\
\hline$\phi_{\text {tot }}$ & Original overall exergetic efficiency [\%] & 0 & Values at the environment state \\
\hline \multirow[t]{2}{*}{$\phi_{\text {tot }}^{\prime}$} & Modified overall exergetic efficiency [\%] & & \\
\hline & & \multicolumn{2}{|l|}{ Superscripts } \\
\hline \multicolumn{2}{|c|}{ Abbreviations } & $\mathrm{AV}$ & Avoidable \\
\hline $\mathrm{AHX}$ & Auxiliary heat exchanger & EN & Endogenous \\
\hline CAES & Compressed air energy storage & EX & Exogenous \\
\hline $\mathrm{CHX}$ & Cold heat exchanger & UN & Unavoidable \\
\hline CMP & Compressor & chg & Charge process \\
\hline CSP & Concentrating solar power & dis & Discharge process \\
\hline
\end{tabular}




\section{Introduction}

The world is in the transition towards enlarging the exploitation of renewable energy sources (RESs) to tackle the severe environmental problems caused by the utilisation of traditional fossil fuels [1]. However, the high penetration of RESs poses a threat to electric power systems [2], which is attributed to their nature of intermittence, inherent instability and low predictability [3]. To cope with these challenges, operational flexibility of power systems, which is defined as the technical capability of a power unit to modulate electrical power inputs to the grid and/or power outputs from the grid over time [4], has attracted great interest from engineers and researchers worldwide, such as those in France [5], Croatia [6], Portugal [7] and China [8].

Operational flexibility can be improved via supply-side, demand-side and network-side approaches [9]. Conventional thermal power plants are considered as a flexible option in the supple-side approach because they can quickly and dynamically regulate the output power according to the load demand, especially in gas-fired power plants [10], lignite poly-generation systems driven by solar energy [11] and coal-fired power plants by regulating thermal system configurations [12] and revising control strategies for water-fuel ratio [13]. Programmes for demand response and demand flexibility are well-adopted ancillary services in the demand-side approach to reduce peak demands in grids by altering the power consumption strategy [14]. Electrical energy storage (EES) technologies are regarded as an important method in the network-side approach to solve the mismatch of electricity supply and demand and enhance the flexibility and stability of the grid [15]. EES technologies can be categorised on the basis of the form of energy they store as mechanical, electro-chemical, electrical, thermo-chemical, chemical and thermal energy storage [16]. Pumped hydro storage [17] and compressed air energy storage (CAES) [18] are two commercially available energy storage technologies for large-scale electricity storage. Some co-generation systems, such those based on solid oxide fuel cells and CAES [19] and a combination of green CAES with various low- and medium-temperature waste heat recovery cycles, such as the organic Rankine cycle (ORC) and the Kalina cycle [20], have been proposed. Although these options are widely deployed worldwide and have high durability, they also feature a number of drawbacks, such as geographical/geological constraints, environmental issues and long construction times [21]. Therefore, the development of alternative energy storage technologies is strongly encouraged. From these efforts, two recently proposed medium-to-large-scale thermo-mechanical energy storage technologies, namely liquid air energy storage (LAES) [22] and pumped thermal electricity storage (PTES) [23], have emerged. A thermo-economic analysis and comparison of these two technologies [24] showed that PTES can achieve higher roundtrip efficiencies and appears to be economically more competitive at higher electricity-buying prices whereas LAES has lower power/energy capital costs and a lower levelised cost of storage (LCOS). In addition, the efficiency of LAES could be enhanced by utilising waste heat/cold streams, such as a novel LAES combined with high-temperature thermal energy storage, thermoelectric generators and the ORC cycle [25]. Thus, LAES and PTES systems, which are characterised with no geographical constraints, long lifetimes and flexible power ratings, may potentially serve as key options in future electric power systems [26].

A PTES system transforms off-peak electricity into thermal energy and stores it inside thermal reservoirs using a heat pump (HP) cycle; a heat engine (HE) cycle that transforms stored thermal energy back into electricity is then followed. Because the main components of PTES systems have no technical limitation, this type of system has drawn increased attention in recent years. The Joule-Brayton cycle is widely employed in PTES systems and sparked great research interest. Solid thermal reservoirs can be used to store thermal energy in a PTES system. Desrues et al. [27] developed a numerical model to illustrate the feasibility of the process and illustrated that the development of reciprocating compressors and expanders with higher polytropic efficiencies could lead to lowertemperature and smaller-scale applications with decent storage efficiencies of up to $67 \%$. The specific heat transfer characteristics of reciprocating devices have been investigated in other studies [28]. White et al. first presented an analysis of wave propagation [29] and thermodynamic losses [30] in solid packed-bed thermal reservoirs due to irreversible heat transfer and frictional effects and then focused on the thermodynamic aspects of PTES systems, including their energy and power densities, the various sources of irreversibility and their 
impact on the roundtrip efficiency [31]. The sensitivity of roundtrip efficiency to various loss parameters revealed particular susceptibility to compression and expansion irreversibility [32]. The results also demonstrated that the cycle performance for specific compression and expansion efficiencies was controlled chiefly by the ratio between the highest and lowest temperatures in each reservoir rather than by the cycle pressure ratio [33]. Benato et al. proposed a new PTES configuration that adopted an electric heater to convert electricity into thermal energy and investigated the effects of two heat transfer fluids, nine storage materials and different control strategies on the PTES system performance [34]. The results revealed that the roundtrip efficiency peaks (27\%) at a temperature of $950{ }^{\circ} \mathrm{C}$ with air as the working fluid [35]. If the grid required high power for a short period of time (e.g. lower than $3 \mathrm{~h}$ ), storages made of concrete spheres could be adopted; if the requirement was high power for a long period of time (e.g. 4-5 h), hematite $\left(\mathrm{Fe}_{2} \mathrm{O}_{3}\right)$ or magnetite $\left(\mathrm{Fe}_{3} \mathrm{O}_{4}\right)$ could be used [36]. Smallbone et al. [37] presented an economic analysis of a PTES system using data obtained during the development of the world's first grid-scale demonstrator project by Newcastle University. The LCOS for a PTES system with a demonstrator size of $2 \mathrm{MW}$ power and a capacity of $16 \mathrm{MWh}$ ranged between 0.07 and $0.11 € / \mathrm{kWh}$. Chen et al. [38] proposed a high-temperature PTES system based on an additional electric heater and integrated with a parallel ORC to recover waste heat due to the irreversibility of the heating and compression/expansion processes. Results revealed that the combination of a high-temperature PTES with ORC represented a large-scale energy storage technology with the roundtrip efficiency of $48 \%$ and the energy storage density of $218.7 \mathrm{MJ} / \mathrm{m}^{3}$. Markides et al. presented a thermo-economic analysis and comparison of PTES and LAES systems and demonstrated that, at the system size intended for commercial applications, LAES (12 MW, $50 \mathrm{MWh}$ ) had a lower capital cost and LCOS than PTES (2 MW, 11.5 MWh). However, when considering the required sell-to-buy price ratio, PTES appeared to be economically more competitive beyond an electricity buy price of $\sim 0.15 \$ / \mathrm{kWh}$, primarily because of its higher roundtrip efficiency [24]. The authors also integrated the characteristics of these technologies into a whole-electricity system assessment model and assessed the corresponding system-level values in various scenarios for system decarbonisation [39]. Wang et al. developed expressions of thermal front propagation and unbalanced mass flow rates between the inflow and outflow of packed beds in a PTES system [40] and proposed a transient analysis method for assessing system coupling dynamics, heat transfer and thermodynamics [41]. The relevant influencing factors, such as the pressure ratio, polytropic efficiency, particle diameters and structures of thermal energy storage reservoirs, were also analysed. The results indicated that helium $(\mathrm{He})$ with a roundtrip efficiency of $57 \%$ presented an advantage over argon (Ar) with an efficiency of $39 \%$.

Compared with solid thermal reservoirs, Joule-Brayton PTES systems with liquid thermal tanks present a number of benefits: (1) the storage liquid may not need to be pressurised which can remarkably reduce the cost of the storage tanks; (2) PTES systems can benefit from this operational experience and cost reductions obtained from the wide deployment of several relevant fluids for concentrating solar power (CSP) plants [42]; (3) finally, hybrid systems that can meet different demands, such as heating, cooling and electricity, may be designed by taking advantage of the indirect heat transfer between a liquid storage material and a working fluid. Many scholars have performed valuable investigations on this topic. Vinnemeier et al. [43] assessed the thermodynamic potential of integrating PTES systems into different types of thermal plants to create large-scale electricity storage units. The results revealed that the roundtrip efficiencies of different heat integration options into different types of thermal plants were roughly in the range of 50\%-60\%. Laughlin [44] proposed a PTES system with liquid thermal storage tanks that could transfer heat from a cryogenic storage fluid to molten solar salt. In this investigation, the roundtrip efficiency, which was computed as a function of the turbomachinery polytropic efficiency and total heat exchanger steel mass, was found to be similar to that of pumped hydroelectric storage. Farres-Antunez et al. [45] reported a novel combined system in which PTES was operated as a topping cycle and LAES was used as a bottoming cycle. Results indicated that the cycle had a roundtrip efficiency similar to that of the separate systems but provided a significantly larger energy density. The best-combined cycle achieved an increase in thermodynamic efficiency of approximately $10 \%$ (from $60 \%$ to $70 \%$ ). Farres-Antunez et al. [46] also proposed two different configurations of 
solar-PTES systems in which an existing CSP plant was retrofitted with a Brayton heat pump or a new hybrid plant used the Brayton cycle for charge/discharge. Results indicated that heat-to-work efficiencies of approximately $40 \%$ (during CSP operation) and roundtrip efficiencies of 55\%-60\% (during PTES operation) could be achieved with state-of-the-art components in the two schemes. McTigue et al. [47] introduced a PTES variant using supercritical carbon dioxide $\left(\mathrm{sCO}_{2}\right)$ as the working fluid. Results revealed that the $\mathrm{SCO}_{2}$-PTES cycle achieved high roundtrip efficiencies for a given hot-storage temperature (up to $78 \%$ at $560{ }^{\circ} \mathrm{C}$ ). A comparative study of adiabatic-CAES and PTES developed by Xue [48] illustrated that the former had a higher roundtrip efficiency $(70 \%-80 \%)$ than the latter (50\%-60\%), whilst the latter enjoyed higher energy density than the former.

The improvement in roundtrip efficiency are amongst the primary targets for a PTES system; this improvement can be achieved by reducing various sources of irreversibility and exergy dissipation to the surroundings. Therefore, performing an exergy analysis based on the second law of thermodynamics is essential. Conventional exergy analyses can only obtain the overall exergetic efficiency and exergy destruction of an investigated system to determine the component with the largest irreversibility generation. By comparison, advanced exergy analyses, where the exergy destruction is split into avoidable/unavoidable and endogenous/exogenous components [49], can not only identify the component with the largest irreversibility generation, but also determine the components on which design improvement efforts should focus. Such an analysis could also quantify the efficiency improvement potential of the system [50].

Advanced exergy analyses have been extended to many types of energy conservation systems. Wang et al. [51] investigated a $2 \mathrm{MW}$ underwater CAES system using conventional and advanced exergy analyses. The author pointed out that the theoretical maximum efficiency under the unavoidable condition was $84 \%$. Liu et al. [52] presented a comprehensive investigation on a novel two-stage transcritical compressed $\mathrm{CO}_{2}$ energy storage system using conventional and advanced exergy analyses. Results indicated that the first compressor possessed the highest potential for improvement because its largest avoidable exergy destruction rate (159 kW) accounted for $23 \%$ of the total avoidable exergy destruction and $12 \%$ of the total exergy destruction. Ebrahimi et al. [53] performed conventional and advanced exergy analyses of a grid-connected underwater CAES facility. The advanced exergy analysis illustrated that $24 \%$ of the exergy destruction was unavoidable. He et al. [54] performed conventional and advanced exergy analyses to evaluate the performance of CAES and supercritical compressed $\mathrm{CO}_{2}$ energy storage (SC-CCES) systems. Results showed that the exergy efficiency of the SC-CCES system, at $57 \%$, was better than that of CAES (51\%); moreover, the interactions amongst different components were not extensive because the endogenous exergy destruction rates of the components were larger than the exogenous exergy destruction rates in CAES and SC-CCES. Idrissa and Boulama [55] investigated a combined Brayton/Brayton power cycle using the advanced exergy analysis. Results illustrated that most of the irreversibility generated at the combustion chamber was endogenous (i.e. approximately two-thirds) and unavoidable ( $86 \%)$; by contrast, the irreversibility generated at both turbines and both compressors was largely endogenous and avoidable.

Galindo et al. [56] performed an analysis of a bottoming ORC cycle coupled to an internal combustion engine by using conventional and advanced exergy analyses. The advanced exergy analysis suggested that the priority of improvement should be the expander, followed by the pump, the condenser and the boiler. Razmi et al. [57] proposed an exergo-economic analysis for a co-generation system composed of a CAES, an ORC cycle and an absorption-compression refrigeration cycle; their results illustrated that the respective costs of electricity and chilled water were $0.08 \$ / \mathrm{kWh}$ and $0.18 \$ / \mathrm{kWh}$ during the peak period. Boyaghchi and Molaie performed an advanced exergy analysis of a real combined cycle power plant with supplementary firing and presented a parametric study discussing the sensitivity of various performance indicators [58]. Results showed that the combustion chamber concentrated most of the exergy destruction (i.e. over 62\%), dominantly in an unavoidable endogenous form; With increasing the turbine inlet temperature and compressor pressure ratio, the avoidable endogenous exergy destruction increased and multiplied by the factors of 1.3 and 8.6, respectively [59]. Wang et al. [60] proposed a cascade absorption heat transformer to utilise industrial low-grade waste heat and used conventional and advanced 
exergy analyses to determine the cause and avoidable degree of exergy destruction. Results revealed that only $21 \%$ of the exergy destruction rates was avoidable by improvement. Fallah et al. performed conventional and advanced exergy analyses to provide detailed information about the improvement potential of the system components for a Kalina cycle [61], a recompression $\mathrm{sCO}_{2}$ cycle [62] and a steam injection gas turbine system [63].

To the authors' best knowledge, various irreversibility and exergy losses in the Joule-Brayton PTES system based on solid thermal reservoirs have been presented via conventional exergy analyses. Compared with a Joule-Brayton PTES system using solid thermal reservoirs, PTES systems using liquid thermal tanks present some attractive advantages, such as lower storage tank costs and the potential design of hybrid systems. However, current studies on PTES systems based on liquid thermal tanks mainly focus on parametric analyses of different hybrid systems and efficiency comparisons with other energy storage technologies; no conventional and advanced exergy analyses have yet been reported for the PTES systems.

The main novelty and contributions of this study are three-fold. (1) The thermodynamic parameter design of the Joule-Brayton PTES system using liquid thermal stores (i.e. solar salt for high-temperature thermal storage and Therminol 66 for intermediate-temperature thermal storage) is performed. (2) Conventional and advanced exergy analyses for non-recuperated and recuperated PTES systems are proposed and compared, and the components on which design improvement efforts should focus are obtained. (3) A quantitative analysis of the overall system performance improvement potential of the recuperated PTES system obtained by improving key parameters related to the turbomachines and heat exchangers is also conduced, and the maximum overall system performance improvement potential is provided. The results of the exergy analyses provide valuable insights into the design, analysis and assessment of large-scale PTES systems.

The rest of this paper is organised as follows. The system description, mathematical models of the main components, exergy analysis models, assumptions and modelling validation are described in Section 2. Detailed conventional and advanced exergy analyses and a quantitative analysis of performance improvement potential are carried out in Section 3. Finally, conclusions are drawn in Section 4.

\section{Methods}

The system configuration of the Joule-Brayton PTES system using liquid thermal stores is first introduced. The models of the investigated PTES system are then provided according to the thermodynamic properties of the main components, and exergy analysis is used to illustrate the main sources of exergy destruction and dissipation in the system. Some assumptions and conditions are further described to develop the system models, and all the models of the system are verified. This section provides these modelling details.

\subsection{System description}

The layout of the Joule-Brayton PTES system using liquid thermal stores during the charge and discharge processes is shown in Fig. 1. The system consists of hot and cold heat exchangers (HHXs and CHX) and each heat exchanger is coupled with high-temperature and low-temperature liquid thermal tanks, four turbomachines (one compressor [CMP] + expander [EXP] pair for charge and another CMP + EXP pair for discharge), two auxiliary heat exchangers (AHX1 and AHX2) in the baseline design and a recuperator (RCT), in case recuperation is considered. A T-s diagram of a JouleBrayton PTES system using liquid stores is shown in Fig. 2.

For the non-recuperated PTES system, during the charge process (the HP cycle), as shown in Fig. 1 (a), the working fluid is first compressed in a CMP. Heat from the compressed and hot working fluid is then transferred to the liquid storage material in the HHXs so that thermal energy is stored in the hot liquid tanks. Thereafter, the working fluid flows to an EXP to produce power and decrease the temperature of the working fluid to its lowest value. Finally, the working fluid transfers cold thermal energy to the liquid storage material in the cold liquid tanks. During the discharge process (the HE cycle), as shown in Fig. 1 (b), the cold working fluid from the CHX is first compressed and enters the HHXs. The storage material in the hot liquid tanks transfers the hot thermal energy stored during the 
charge process back to the working fluid, and then the working fluid produces power in an EXP, which is converted into electricity output. Subsequently, the exhaust gas is cooled by the cold thermal energy from the storage material in the cold liquid tanks. AHX1 and AHX2 are used to reject the extra heat to the environment and maintain identical temperature profiles in the hot and cold liquid tanks during the charge and discharge processes. If a RCT is added to the PTES system (i.e. the recuperated PTES system), the gas temperature at the CMP inlet can be enhanced by absorbing the heat from the gas at the $\mathrm{HHX}$ outlet during charge, and some of the thermal energy of the gas at the EXP outlet can be absorbed before it is rejected to the environment during discharge.

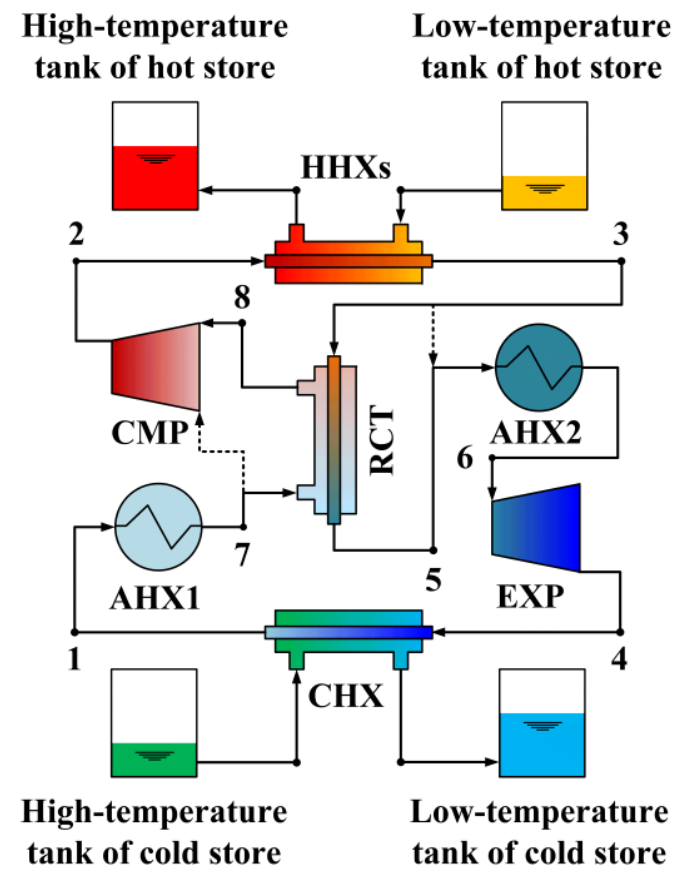

(a) Charge process

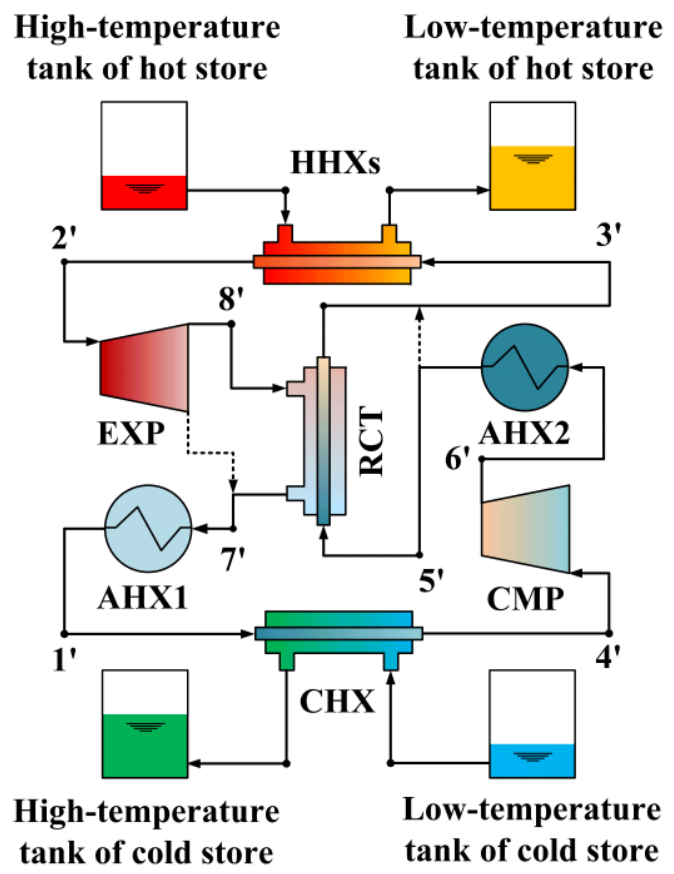

(b) Discharge process

Fig. 1 Layout of Joule-Brayton PTES system using liquid thermal stores. CMP: compressor; EXP: expander; RCT: recuperator; $\mathrm{HHX/CHX:} \mathrm{hot/cold} \mathrm{heat} \mathrm{exchanger;} \mathrm{AHX}$ : auxiliary heat exchanger.

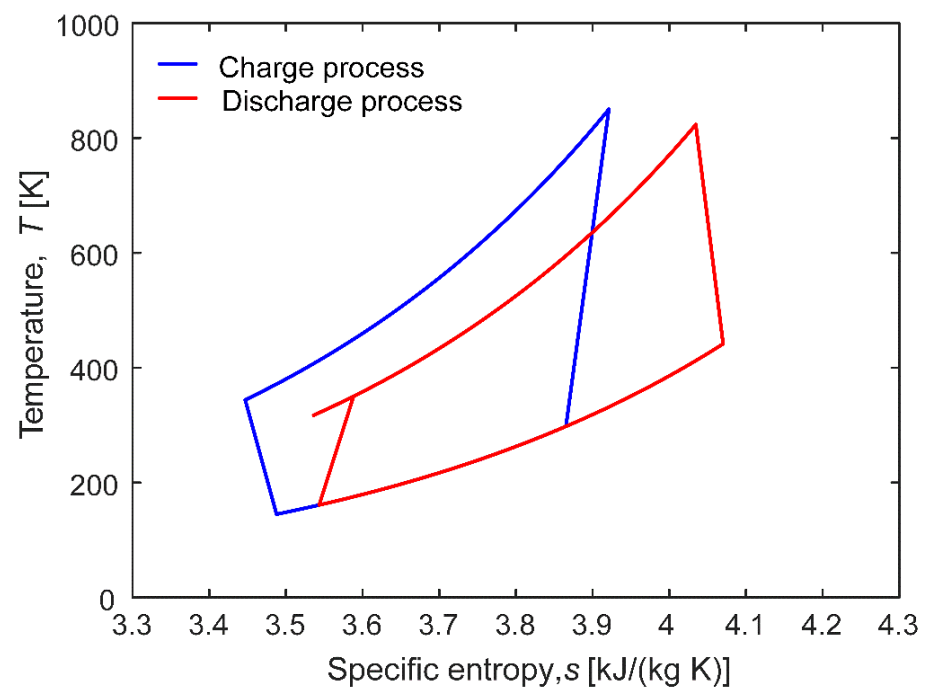

Fig. 2 T-s diagram of Joule-Brayton PTES system using liquid thermal stores and argon as the working fluid.

In the present investigation, Argon is selected as the working fluid because of its low compression ratio and 
high adiabatic efficiency [32, 37, 44]. Solar salt is used in the hot thermal storage tanks as the liquid storage material because of its robust performance under high-temperature conditions (533-873 K) [45]. However, because the minimum working temperature of solar salt is much higher than the ambient temperature, an intermediate-temperature liquid storage material is also required; Therminol 66 , which has a working temperature range of 264-616 K, is the preferred choice for this case [64]. Empirical correlations are used to calculate the thermo-physical properties of all hot storage materials, which are summarised in Table 1. Butane $\left(\mathrm{C}_{4} \mathrm{H}_{10}\right)$ is selected as the cold thermal energy storage material because its freezing point is equal to $135 \mathrm{~K}$; thus, $\mathrm{C}_{4} \mathrm{H}_{10}$ can maximise the operational temperature range of the PTES system and improve its overall efficiency. The thermodynamic properties are obtained from REFPROP 9.1 software [65].

Table 1 Correlation for thermophysical properties of solar salt and Therminol 66, $T(\mathrm{~K})$.

\begin{tabular}{|c|c|c|}
\hline \multirow{2}{*}{$\begin{array}{l}\text { Thermo-physical } \\
\text { properties }\end{array}$} & \multicolumn{2}{|l|}{ Empirical correlation } \\
\hline & Solar salt [42] & Therminol 66 [64] \\
\hline Density, $\rho\left[\mathrm{kg} / \mathrm{m}^{3}\right]$ & $2090-0.636 \times(T-273.15)$ & $1164.45-0.4389 \times T-3.21 \times 10^{-4} \times T^{2}$ \\
\hline $\begin{array}{l}\text { Specific heat capacity, } \\
c_{p}[\mathrm{~J} /(\mathrm{kg} \cdot \mathrm{K})]\end{array}$ & $1443+0.172 \times(T-273.15)$ & $658+2.82 \times T+8.97 \times 10^{-4} \times T^{2}$ \\
\hline $\begin{array}{l}\text { Thermal conductivity, } k \\
{[\mathrm{~W} /(\mathrm{m} \cdot \mathrm{K})]}\end{array}$ & $0.443+1.9 \times 10^{-4} \times(T-273.15)$ & $0.116+4.9 \times 10^{-5} \times T-1.5 \times 10^{-7} \times T^{2}$ \\
\hline Viscosity, $\mu[\mathrm{Pa} \cdot \mathrm{s}]$ & $\begin{array}{l}2.2714 \times 10^{-2}-1.20 \times 10^{-4} \times(T-273.15)+2.281 \times \\
10^{-7} \times(T-273.15)^{2}-1.474 \times 10^{-10} \times(T-273.15)^{3}\end{array}$ & $\begin{array}{l}\left(1164.45-0.4389 \times T-3.21 \times 10^{-4} \times T^{2}\right) \times \\
\exp [-16.096+586.38 /(T-210.65)]\end{array}$ \\
\hline
\end{tabular}

\subsection{Mathematical models of the components}

The main components of the investigated PTES system include two CMPs, two EXPs, six different heat exchangers (two HHXs, a CHX, two AHXs and an RCT) and high- and low-temperature liquid thermal tanks. The following section describes these models.

\subsubsection{Compression and expansion models}

The isentropic efficiency of a CMP is defined as [52]:

$$
\eta_{\mathrm{CMP}}=\frac{h_{\mathrm{CMP}, \mathrm{is}, \text { out }}-h_{\mathrm{CMP}, \text { in }}}{h_{\mathrm{CMP}, \text { out }}-h_{\mathrm{CMP}, \text { in }}},
$$

where $h_{\mathrm{CMP}, \text { in }}, h_{\mathrm{CMP}, \text { out }}$ and $h_{\mathrm{CMP}, \mathrm{is}, \text { out }}$ are the respective inflow specific enthalpy, outflow specific enthalpy and outflow specific enthalpy occurring in an isentropic process of a CMP.

The actual enthalpy of the working fluid at the outlet of a CMP can be calculated using the definition of compression efficiency. Thus, the specific power consumed in a compression process can be calculated from [55]:

$$
w_{\mathrm{CMP}}=h_{\mathrm{CMP}, \text { out }}-h_{\mathrm{CMP}, \mathrm{in}} .
$$

The calculation method for an actual expansion process is identical to that for a compression process. The isentropic efficiency of an EXP is defined as [52]:

$$
\eta_{\mathrm{EXP}}=\frac{h_{\mathrm{EXP}, \text { in }}-h_{\mathrm{EXP}, \text { out }}}{h_{\mathrm{EXP}, \mathrm{in}}-h_{\mathrm{EXP}, \text { is out }}},
$$

where $h_{\mathrm{EXP}, \text { in }}, h_{\mathrm{EXP}, \text { out }}$ and $h_{\mathrm{EXP}, \mathrm{is}, \text { out }}$ are the respective inflow specific enthalpy, outflow specific enthalpy and outflow specific enthalpy occurring in an isentropic process of an EXP.

The actual enthalpy of the working fluid at the outlet of an EXP can be calculated using the definition of expansion efficiency. Thus, the specific power produced in the expansion process is obtained by [55]: 
$w_{\mathrm{EXP}}=h_{\mathrm{EXP}, \mathrm{in}}-h_{\mathrm{EXP}, \mathrm{out}}$.

In this investigation, the pressure ratios of the CMPs are first calculated during charge and discharge. Then, if the total pressures at the inlet of the CMPs during charge and discharge are supposed to be $p_{0}$, the pressure ratios of the EXPs during charge and discharge can be determined by [41]:

$$
p_{0} \beta_{\mathrm{CMP}}^{\mathrm{chg}}-\Delta p_{\mathrm{HHX}}^{\mathrm{chg}}-\Delta p_{\mathrm{RCT}}^{\mathrm{chg}}=\left(p_{0}+\Delta p_{\mathrm{RCT}}^{\mathrm{chg}}+\Delta p_{\mathrm{CHX}}^{\mathrm{chg}}\right) \beta_{\mathrm{EXP}}^{\mathrm{chg}}
$$

during charge and

$$
p_{0} \beta_{\mathrm{CMP}}^{\mathrm{dis}}-\Delta p_{\mathrm{AHX} 2}^{\mathrm{dis}}-\Delta p_{\mathrm{RCT}}^{\mathrm{dis}}-\Delta p_{\mathrm{HHX}}^{\mathrm{dis}}=\left(p_{0}+\Delta p_{\mathrm{CHX}}^{\mathrm{dis}}+\Delta p_{\mathrm{AHX} 1}^{\mathrm{dis}}+\Delta p_{\mathrm{RCT}}^{\mathrm{dis}}\right) \beta_{\mathrm{EXP}}^{\mathrm{dis}}
$$

during discharge. Here, $\beta_{\mathrm{CMP}}^{\text {chg }}$ and $\beta_{\mathrm{CMP}}^{\text {dis }}$ are the pressure ratios of the CMPs during charge and discharge, respectively; $\beta_{\mathrm{EXP}}^{\text {chg }}$ and $\beta_{\mathrm{EXP}}^{\text {dis }}$ are the pressure ratios of the EXPs during charge and discharge, respectively; and $\Delta p_{k}^{\text {chg }}$ and $\Delta p_{k}^{\text {dis }}$ are the pressure drops in the $k$ th component during charge and discharge, respectively.

\subsubsection{Heat exchanger model}

Heat exchangers play an important role in PTES systems and must be analysed carefully. The performance of a heat exchanger is usually evaluated in terms of its effectiveness, which is the ratio of the actual heat transfer rate $\dot{Q}$ to the theoretical maximum heat transfer rate $\dot{Q}_{\max }[66]$ :

$$
\varepsilon=\dot{Q} / \dot{Q}_{\max }
$$

Following the energy conservation law, the actual heat transfer rate is expressed as [54]:

$$
\dot{Q}=\dot{m}_{\mathrm{h}} c_{\mathrm{p}, \mathrm{h}}\left(T_{\mathrm{h}, \mathrm{in}}-T_{\mathrm{h}, \mathrm{out}}\right)=\dot{m}_{\mathrm{c}} c_{\mathrm{p}, \mathrm{c}}\left(T_{\mathrm{c}, \mathrm{out}}-T_{\mathrm{c}, \mathrm{in}}\right)
$$

If all of the fluids have constant specific heat capacities $c_{p}$, the theoretical maximum heat transfer rate is equal to [66],

$$
\dot{Q}_{\max }=\left(\dot{m} c_{\mathrm{p}}\right)_{\min }\left(T_{\mathrm{h}, \mathrm{in}}-T_{\mathrm{c}, \mathrm{in}}\right) \text {, }
$$

where $\left(\dot{m} c_{\mathrm{p}}\right)_{\min }$ is the smaller of the heat-capacity rates of the hot and cold fluids. However, if the fluids have a nonconstant $c_{p}$, the theoretical maximum heat transfer rate depends on the location of the pinch point that may occur at the cold inlet, the hot inlet or in the middle of the heat exchanger. The following three integrals must be computed to identify where the pinch point occurs in each case and determine the theoretical maximum heat transfer rate [67]:

$$
\dot{Q}_{1}=\dot{m}_{\mathrm{h}} \int_{T_{\mathrm{c}, \mathrm{in}}}^{T_{h, \text { in }}} c_{\mathrm{p}, \mathrm{h}} d T
$$

corresponding to $T_{\text {pinch }}=T_{\text {c,in }}$,

$$
\dot{Q}_{2}=\dot{m}_{c} \int_{T_{\mathrm{c}, \mathrm{in}}}^{T_{h, \mathrm{in}}} c_{\mathrm{p}, \mathrm{c}} d T
$$

corresponding to $T_{\text {pinch }}=T_{\mathrm{h}, \text { in }}$ and

$$
\dot{Q}_{3}=\dot{m}_{c} \int_{T_{\mathrm{c}, \text { in }}}^{T_{\text {pinch }}} c_{\mathrm{p}, \mathrm{c}} d T+\dot{m}_{\mathrm{h}} \int_{T_{\mathrm{pinch}}}^{T_{h, \text { in }}} c_{\mathrm{p}, \mathrm{h}} d T
$$

where $T_{\text {pinch }}$ is the temperature at the pinch point. For the temperature-variant $c_{p}$ scenario, the local heat capacity rates of both fluids must be equal at the pinch point [67]:

$$
\left(\dot{m} c_{\mathrm{p}}\right)_{\mathrm{c}}=\left(\dot{m} c_{\mathrm{p}}\right)_{\mathrm{h}} \text { at } T=T_{\text {pinch }},
$$

by numerically solving Eq. (13) for each pair of $c_{p}(T)$ functions, one can obtain $T_{\text {pinch }}$.

Therefore, the maximum heat transfer rate must be the minimum of the three previous integrals [67]: 
$\dot{Q}_{\max }=\min \left(\dot{Q}_{1}, \dot{Q}_{2}, \dot{Q}_{3}\right)$.

The outflow temperature of the hot and cold fluids can be determined using Eqs. (7)-(13). The exergy analyses are facilitated by defining the pressure loss factor of a heat exchanger as follows [55]:

$f_{\mathrm{p}}=\Delta p / p_{\mathrm{in}}$.

\subsubsection{Liquid storage tank model}

The insulation factor of liquid storage tanks is defined as the ratio of the internal energies of the storage fluid between the charge and discharge processes [68]:

$$
\kappa=\frac{E_{s}^{\prime}}{E_{\mathrm{s}}}=\frac{\dot{m}_{\mathrm{s}} c_{\mathrm{p}, \mathrm{s}}\left(T_{\mathrm{s}}^{\prime}-T_{0}\right)}{\dot{m}_{\mathrm{s}} c_{\mathrm{p}, \mathrm{s}}\left(T_{\mathrm{s}}-T_{0}\right)},
$$

where $\dot{m}_{\mathrm{s}}$ is the mass flow rate of the storage liquid; $C_{\mathrm{p}, \mathrm{s}}$ is the specific heat capacity of the storage liquid; $T_{\mathrm{s}}$ and $T_{\mathrm{s}}^{\prime}$ are the respective temperatures of the storage liquid between the charge and discharge processes; and $T_{0}$ is the ambient temperature.

\subsection{Exergy analysis methods}

Because the chemical-reaction, kinetic and potential exergies of fluids in the PTES system are negligible, only the physical exergy is considered. The total exergy of a stream can be expressed as [60]:

$$
\dot{E}_{\mathrm{x}}=\dot{m} \cdot e_{\mathrm{x}}=\dot{m} \cdot\left[\left(h-h_{0}\right)-T_{0}\left(s-s_{0}\right)\right] .
$$

An isobaric process is assumed for the liquid storage materials in the system. Thus, the specific exergy difference of the storage liquid between the inlet and outlet of the HHXs and $\mathrm{CHX}$ can be obtained by [62]:

$$
\Delta e_{\mathrm{x}}=\Delta h-T_{0} \cdot \Delta s=\bar{c}_{\mathrm{p}}\left(T_{\text {out }}-T_{\text {in }}-T_{0} \ln \frac{T_{\text {out }}}{T_{\text {in }}}\right),
$$

where $T_{\text {in }}$ and $T_{\text {out }}$ respectively denote the inlet and outlet temperatures of the storage liquid and $\bar{c}_{\mathrm{p}}$ is the mean specific heat capacity.

Compared with the engineering, structural theory and equivalent components methods, the thermodynamic cycle method is better suited to and provides higher prediction accuracy for advanced exergy analyses [53]. Therefore, this method is selected to investigate the PTES system. In the thermodynamic cycle method, real, unavoidable and ideal cycles are applied to calculate different exergy destruction components. Table 2 summarises the detailed parameter settings of these cycles. In a real cycle, the isentropic efficiencies of the CMP and EXP are set to $85 \%$ [55], the effectiveness of the three different heat exchangers are set to 0.9 [41] and their corresponding pressure loss factors are set to $2 \%$ [61]. The ideal cycle is defined with the same component arrangements as the real cycle, but the isentropic CMP, the isentropic EXP and heat exchangers that have zero pressure drops and zero temperature differences are considered. The intermediate unavoidable cycle is defined with a very small but finite irreversibility for each component, which means the isentropic efficiencies of the CMP and EXP are equal to 95\% [51, $61,62,69$ ], the effectivenesses of all heat exchangers are equal to 0.98 and their pressure loss factors are equal to $0.5 \%[51,55]$. These numbers are assumed to represent technological limitations that are impossible to overcome in the foreseeable future. Exergy dissipation to the environment is only considered for the AHXs and hot/cold liquid storage tanks. The input parameters, including the pressure drop factor of all AHXs $(0.5 \%)$ and the insulation factor of all hot and cold storage tanks (99\%), are fixed for all three cycles [51]. 
Table 2 The main assumption for the PTES system under real, unavoidable and ideal cycles.

\begin{tabular}{lllll}
\hline Components & Parameters & Real & Unavoidable & Ideal \\
\hline Compressor & Isentropic efficiency, $\eta_{\mathrm{CMP}}$ & $85 \%[55]$ & $95 \%[51,62,69]$ & $100 \%$ \\
Expander & Isentropic efficiency, $\eta_{\mathrm{EXP}}$ & $85 \%[55]$ & $95 \%[61,62,69]$ & $100 \%$ \\
Hot heat exchanger & Effectiveness, $\varepsilon_{\mathrm{HHX}}$ & $0.9[41]$ & $0.98[51]$ & 1.0 \\
& Pressure loss factor, $f_{\mathrm{p}, \mathrm{HHX}}$ & $2 \%[61]$ & $0.5 \%[55,61]$ & $0 \%$ \\
Cold heat exchanger & Effectiveness, $\varepsilon_{\mathrm{CHX}}$ & $0.9[41]$ & $0.98[51]$ & 1.0 \\
& Pressure loss factor, $f_{\mathrm{p}, \mathrm{CHX}}$ & $2 \%[61]$ & $0.5 \%[55,61]$ & $0 \%$ \\
\multirow{2}{*}{ Recuperator } & Effectiveness, $\varepsilon_{\mathrm{RCT}}$ & $0.9[41]$ & $0.98[51]$ & 1.0 \\
& Pressure loss factor, $f_{\mathrm{p}, \mathrm{RCT}}$ & $2 \%[61]$ & $0.5 \%[55,61]$ & $0 \%$ \\
\hline
\end{tabular}

\subsubsection{Conventional exergy analysis}

According to the exergy balance equation, the exergy destruction rate of the $k$ th component is calculated as [52]:

$$
\dot{E}_{\mathrm{D}, k}=\dot{E}_{\mathrm{F}, k}-\dot{E}_{\mathrm{P}, k},
$$

where $\dot{E}_{\mathrm{D}, k}, \dot{E}_{\mathrm{F}, k}$ and $\dot{E}_{\mathrm{P}, k}$ are the respective exergy destruction, fuel exergy and product exergy rates of the $k$ th component.

The initial exergetic efficiency of the $k$ th component, $\phi_{k}$, is calculated by [52]:

$$
\phi_{k}=\frac{\dot{E}_{\mathrm{P}, k}}{\dot{E}_{\mathrm{F}, k}}=\frac{\dot{E}_{\mathrm{F}, k}-\dot{E}_{\mathrm{D}, k}}{\dot{E}_{\mathrm{F}, k}} .
$$

Similarly, the original overall exergetic efficiency of the PTES system, $\phi_{\text {tot, }}$ can be expressed by [52]:

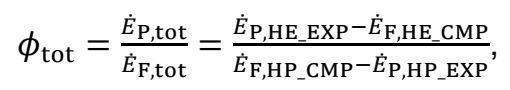

where subscripts HP and HE respectively refer to the charge (heat pump) and discharge (heat engine) processes. The exergy destruction rates of distinct components are compared by defining the exergy destruction ratio of the $k$ th component, $y_{\mathrm{D}, k}$, and the relative exergy destruction, $y_{\mathrm{D}, k}^{\prime}$, as follows [52]:

$$
\begin{aligned}
& y_{\mathrm{D}, k}=\frac{\dot{E}_{\mathrm{D}, k}}{\dot{E}_{\mathrm{F}, k}}, \\
& y_{\mathrm{D}, k}^{\prime}=\frac{\dot{E}_{\mathrm{D}, k}}{\sum_{k} \dot{E}_{\mathrm{D}, k}} \times 100 \% .
\end{aligned}
$$

The definitions of the fuel exergy, product exergy and exergy destruction rates of different components in the PTES system are introduced in Table 3.

Table 3Fuel exergy, product exergy and exergy destruction rates of the main components for the PTES system [54].

\begin{tabular}{llll}
\hline Components & $\dot{E}_{\mathrm{F}, k}$ & $\dot{E}_{\mathrm{P}, k}$ & $\dot{E}_{\mathrm{D}, k}$ \\
\hline Compressor & $W_{\mathrm{CMP}}$ & $\dot{E}_{\mathrm{out}, \mathrm{CMP}}-\dot{E}_{\mathrm{in}, \mathrm{CMP}}$ & $\dot{E}_{\mathrm{F}, \mathrm{CMP}}-\dot{E}_{\mathrm{P}, \mathrm{CMP}}$ \\
Expander & $\dot{E}_{\mathrm{in}, \mathrm{EXP}}-\dot{E}_{\mathrm{out}, \mathrm{EXP}}$ & $W_{\mathrm{EXP}}$ & $\dot{E}_{\mathrm{F}, \mathrm{EXP}}-\dot{E}_{\mathrm{P}, \mathrm{EXP}}$ \\
Heat exchanger & $\dot{E}_{\mathrm{h}, \mathrm{in}, \mathrm{HEX}}-\dot{E}_{\mathrm{h}, \mathrm{out}, \mathrm{HEX}}$ & $\dot{E}_{\mathrm{c}, \mathrm{out}, \mathrm{HEX}}-\dot{E}_{\mathrm{c}, \mathrm{in}, \mathrm{HEX}}$ & $\dot{E}_{\mathrm{F}, \mathrm{HEX}}-\dot{E}_{\mathrm{P}, \mathrm{HEX}}$ \\
Recuperator & $\dot{E}_{\mathrm{h}, \mathrm{in}, \mathrm{RCT}}-\dot{E}_{\mathrm{h}, \mathrm{out}, \mathrm{RCT}}$ & $\dot{E}_{\mathrm{c}, \mathrm{out}, \mathrm{RCT}}-\dot{E}_{\mathrm{c}, \mathrm{in}, \mathrm{RCT}}$ & $\dot{E}_{\mathrm{F}, \mathrm{RCT}}-\dot{E}_{\mathrm{P}, \mathrm{RCT}}$ \\
Storage tank & $\dot{E}_{\mathrm{in}, \mathrm{STK}}$ & $\dot{E}_{\mathrm{out}, \mathrm{STK}}$ & $\dot{E}_{\mathrm{F}, \mathrm{STK}}-\dot{E}_{\mathrm{P}, \mathrm{STK}}$ \\
\hline
\end{tabular}




\subsubsection{Advanced exergy analysis}

The overall exergetic efficiency and exergy destruction rates of the PTES system are calculated on the conventional exergy analysis to determine the component with the largest irreversibility generation. Advanced exergy analysis is applied as a useful tool to evaluate which components in the system should be the focus of improvement efforts and provide an accurate assessment of performance improvement potential of the system. In this analysis method, the exergy destruction is split into detailed components, namely, avoidable exergy destruction, unavoidable exergy destruction, endogenous exergy destruction and exogenous exergy destruction. The avoidable and unavoidable exergy destruction properties are split further into endogenous and exogenous components [54].

The exergy destruction rate within the kth component can be calculated as the sum of the endogenous exergy destruction rate, $\dot{E}_{\mathrm{D}, k}^{\mathrm{EN}}$, resulting from the operation of the component itself and the exogenous exergy destruction rate, $\dot{E}_{\mathrm{D}, k}^{\mathrm{EX}}$, resulting from the operation of other components of the system [60]:

$$
\dot{E}_{\mathrm{D}, k}=\dot{E}_{\mathrm{D}, k}^{\mathrm{EN}}+\dot{E}_{\mathrm{D}, k}^{\mathrm{EX}}
$$

Technological limitations, such as those related to the availability and cost of materials and manufacturing methods for each component in the near future, are imposed to determine the unavoidable exergy destruction. Thus, the exergy destruction rate within the $k$ th component can be split into unavoidable and avoidable exergy destruction rates as follows [60]:

$$
\dot{E}_{\mathrm{D}, k}=\dot{E}_{\mathrm{D}, k}^{\mathrm{UN}}+\dot{E}_{\mathrm{D}, k}^{\mathrm{AV}}
$$

where $\dot{E}_{\mathrm{D}, k}^{\mathrm{UN}}$ is the unavoidable exergy destruction rate that cannot be reduced because of technological limitations and manufacturing methods and $\dot{E}_{\mathrm{D}, k}^{\mathrm{AV}}$ is the avoidable exergy destruction rate.

As a consequence of the double-splitting in Eqs. (24) and (25), the exergy destruction rate within the $k$ th component can also be calculated by [60]:

$$
\dot{E}_{\mathrm{D}, k}=\dot{E}_{\mathrm{D}, k}^{\mathrm{EN}, \mathrm{AV}}+\dot{E}_{\mathrm{D}, k}^{\mathrm{EN}, \mathrm{UN}}+\dot{E}_{\mathrm{D}, k}^{\mathrm{EX}, \mathrm{AV}}+\dot{E}_{\mathrm{D}, k}^{\mathrm{EX}, \mathrm{UN}},
$$

where $\dot{E}_{\mathrm{D}, k}^{\mathrm{EN}, \mathrm{AV}}$ and $\dot{E}_{\mathrm{D}, k}^{\mathrm{EN}, \mathrm{UN}}$ respectively represent the avoidable and the unavoidable endogenous destruction rates of the $k$ th component and $\dot{E}_{\mathrm{D}, k}^{\mathrm{EX}, \mathrm{AV}}$ and $\dot{E}_{\mathrm{D}, k}^{\mathrm{EX}, \mathrm{UN}}$ respectively represent the avoidable and unavoidable exogenous destruction rates of the $k$ th component.

The different terms in Eq. (26) are obtained by calculating various PTES system parameters under the real cycle to obtain the fuel and product exergy rates $\left(\dot{E}_{\mathrm{F}, k}\right.$ and $\left.\dot{E}_{\mathrm{P}, k}\right)$ and then evaluating the real exergy destruction rate for each component using Eq. (19). The system parameters are subsequently calculated using the unavoidable cycle to obtain the unavoidable exergy destruction rate for each component, which is defined as [55]:

$$
\dot{E}_{\mathrm{D}, k}^{\mathrm{UN}}=\dot{E}_{\mathrm{P}, k}\left(\frac{\dot{E}_{\mathrm{D}, k}}{\dot{E}_{\mathrm{P}, k}}\right)^{\mathrm{UN}} \text {. }
$$

Therefore, the avoidable exergy destruction rate within the $k$ th component, $\dot{E}_{\mathrm{D}, k}^{\mathrm{AV}}$, can be calculated by using Eq. (25). Next, the PTES system parameters are calculated using real cycle settings for the $k$ th component and ideal cycle settings for all other components to obtain the exergy destruction rate exclusively resulting from the operation of the $k$ th component, $\dot{E}_{\mathrm{D}, k}^{\mathrm{EN}}$. Then, the exergy destruction rate due to the operation of the other components of the cycle, $\dot{E}_{\mathrm{D}, k}^{\mathrm{EX}}$, can be obtained using Eq. (24).

The endogenous unavoidable exergy destruction rate is defined in a similar manner as in Eq. (27) [55]:

$$
\dot{E}_{\mathrm{D}, k}^{\mathrm{EN}, \mathrm{UN}}=\dot{E}_{\mathrm{P}, k}^{\mathrm{EN}}\left(\frac{\dot{E}_{\mathrm{D}, k}}{\dot{E}_{\mathrm{P}, k}}\right)^{\mathrm{UN}} \text {. }
$$

The endogenous avoidable exergy destruction rate, $\dot{E}_{\mathrm{D}, k}^{\mathrm{EN}, \mathrm{AV}}$, is obtained by subtracting the endogenous unavoidable exergy destruction rate, $\dot{E}_{\mathrm{D}, k}^{\mathrm{EN}, \mathrm{UN}}$, from the total endogenous exergy destruction rate, $\dot{E}_{\mathrm{D}, k}^{\mathrm{EN}}[55]$ :

$$
\dot{E}_{\mathrm{D}, k}^{\mathrm{EN}, \mathrm{AV}}=\dot{E}_{\mathrm{D}, k}^{\mathrm{EN}}-\dot{E}_{\mathrm{D}, k}^{\mathrm{EN}, \mathrm{UN}} .
$$


The exogenous unavoidable exergy destruction rate, $\dot{E}_{\mathrm{D}, k}^{\mathrm{EX}, \mathrm{UN}}$, is obtained by subtracting the endogenous unavoidable exergy destruction rate, $\dot{E}_{\mathrm{D}, k}^{\mathrm{EN}, \mathrm{UN}}$, from the total unavoidable exergy destruction rate, $\dot{E}_{\mathrm{D}, k}^{\mathrm{UN}}[55]$ :

$$
\dot{E}_{\mathrm{D}, k}^{\mathrm{EX}, \mathrm{UN}}=\dot{E}_{\mathrm{D}, k}^{\mathrm{UN}}-\dot{E}_{\mathrm{D}, k}^{\mathrm{EN}, \mathrm{UN}} .
$$

Finally, the exogenous avoidable exergy destruction rate, $\dot{E}_{\mathrm{D}, k}^{\mathrm{EX}, \mathrm{AV}}$, is calculated by subtracting the exogenous unavoidable exergy destruction rate, $\dot{E}_{\mathrm{D}, k}^{\mathrm{EX}, \mathrm{UN}}$, from the total exogenous exergy destruction rate, $\dot{E}_{\mathrm{D}, k}^{\mathrm{EX}}$, or by subtracting the endogenous avoidable exergy destruction rate, $\dot{E}_{\mathrm{D}, k}^{\mathrm{EN}, \mathrm{AV}}$, from the total avoidable exergy destruction, $\dot{E}_{\mathrm{D}, k}^{\mathrm{AV}}[55]$ :

$$
\dot{E}_{\mathrm{D}, k}^{\mathrm{EX}, \mathrm{AV}}=\dot{E}_{\mathrm{D}, k}^{\mathrm{EX}}-\dot{E}_{\mathrm{D}, k}^{\mathrm{EX}, \mathrm{UN}}=\dot{E}_{\mathrm{D}, k}^{\mathrm{AV}}-\dot{E}_{\mathrm{D}, k}^{\mathrm{EN}, \mathrm{AV}}
$$

The modified exergetic efficiency of the $k$ th component, which could be used to observe the effect of the avoidable exergy destruction on the component itself, is calculated as [70]:

$$
\phi_{k}^{\prime}=\frac{\dot{E}_{\mathrm{P}, k}}{\dot{E}_{\mathrm{F}, k}-\dot{E}_{\mathrm{D}, k}^{\mathrm{AV}}} \text {. }
$$

Similarly, the modified overall exergetic efficiency of the PTES system can be calculated from [70]:

$$
\phi_{\text {tot }}^{\prime}=\frac{\dot{E}_{\mathrm{P}, \text { tot }}}{\dot{E}_{\mathrm{F}, \text { tot }}-\dot{E}_{\mathrm{D}, k}^{\mathrm{AV}}} \text {. }
$$

\subsection{Assumption and conditions}

In this investigation, the power capacity is fixed to $10 \mathrm{MW}$ and the charge/discharge times are set to $6 \mathrm{~h}$. The thermodynamic parameters of the PTES system are optimised using the optimisation method [71] to achieve the highest roundtrip efficiency considering the limitations of the working temperature of the storage materials and the manufacturing capability of the main components in practical applications. A sequential quadratic programming algorithm [72] has been proven to be the most reliable method for solving the optimisation problem. A multi-start strategy that begins from different randomly selected initial points is utilised to prevent the solver from being trapped in local minimum solutions. Several assumptions are further considered:

(1) The system works under steady-state conditions [55].

(2) The heat dissipation to the surroundings is negligible [71].

(3) The pressure losses in the pipelines are ignored [52].

(4) The efficiencies of the motors and generators are assumed to be $98 \%$ [53].

(5) Homogenised parameters are assumed for all liquid storage tanks [73].

\subsection{Modelling validation}

A recompression $\mathrm{sCO}_{2}$ power cycle [62] is selected to validate the correctness and feasibility of the thermodynamic models and exergy analysis methods. The analysis of the $\mathrm{sCO}_{2}$ power cycle is similar to the present investigation in many ways: (a) the same main components (e.g. CMP, EXP and heat exchangers) and influencing factors (e.g. the isentropic efficiency of the CMP and the EXP and the effectiveness and the pressure drop factor of the heat exchangers) are adopted. Here, the thermodynamic parameters are first designed using the same models introduced in Section 3, and a comparison of the main thermodynamic parameters between Ref. [62] and the present calculation results is shown in the Supporting Information. The results illustrate that the simulated models are accurate for the thermodynamic parameter design. Then, the conventional and advanced exergy analyses are performed in the $\mathrm{SCO}_{2}$ power cycle, and a comparison of several exergy destruction rates between the present results and those in Ref. [62] is summarised in Table 4. All of the relative errors between the results predicted by the present models and those in the literature are less than $0.6 \%$, which means the mathematical models of all components and exergy analysis models are all accurate and sufficient for the exergy analysis of the PTES system. 
Table 4 Comparison of the exergy destruction rates of our results with these in Ref. [62] for the $\mathrm{sCO}_{2} \mathrm{Cycle}$.

\begin{tabular}{|c|c|c|c|c|c|c|c|c|c|}
\hline \multirow{2}{*}{$\begin{array}{l}\text { Cycle } \\
\text { components }\end{array}$} & \multicolumn{3}{|c|}{$\dot{E}_{\mathrm{D}, k}(\mathrm{MW})$} & \multicolumn{3}{|c|}{$\dot{E}_{\mathrm{D}, k}^{\mathrm{EN}}(\mathrm{MW})$} & \multicolumn{3}{|c|}{$\dot{E}_{\mathrm{D}, k}^{\mathrm{EX}} \quad(\mathrm{MW})$} \\
\hline & $\begin{array}{l}\text { Present } \\
\text { result }\end{array}$ & Ref. & $\begin{array}{l}\text { Relative } \\
\text { error }\end{array}$ & $\begin{array}{l}\text { Present } \\
\text { result }\end{array}$ & Ref. & $\begin{array}{l}\text { Relative } \\
\text { error }\end{array}$ & $\begin{array}{l}\text { Present } \\
\text { result }\end{array}$ & Ref. & $\begin{array}{l}\text { Relative } \\
\text { error }\end{array}$ \\
\hline Turbine & 19.64 & 19.64 & $0.00 \%$ & 15.36 & 15.36 & $0.00 \%$ & 4.28 & 4.28 & $0.00 \%$ \\
\hline Reactor & 77.32 & 77.32 & $0.00 \%$ & 51.69 & 51.68 & $0.02 \%$ & 25.63 & 25.64 & $0.04 \%$ \\
\hline $\begin{array}{l}\text { High-temperature } \\
\text { recuperator }\end{array}$ & 21.95 & 21.95 & $0.00 \%$ & 18.48 & 18.50 & $0.11 \%$ & 3.47 & 3.45 & $0.58 \%$ \\
\hline $\begin{array}{l}\text { Low-temperature } \\
\text { recuperator }\end{array}$ & 25.05 & 25.13 & $0.32 \%$ & 8.85 & 8.89 & $0.45 \%$ & 16.20 & 16.24 & $0.25 \%$ \\
\hline Main compressor & 13.99 & 14.00 & $0.07 \%$ & 7.61 & 7.61 & $0.00 \%$ & 6.38 & 6.39 & $0.16 \%$ \\
\hline $\begin{array}{l}\text { Recompression } \\
\text { compressor }\end{array}$ & 7.09 & 7.09 & $0.00 \%$ & 4.68 & 4.68 & $0.00 \%$ & 2.41 & 2.41 & $0.00 \%$ \\
\hline Pre-cooler & 48.85 & 48.87 & $0.04 \%$ & 19.76 & 19.76 & $0.00 \%$ & 29.09 & 29.11 & $0.07 \%$ \\
\hline
\end{tabular}

\section{Results and discussion}

In this work, conventional and advanced exergy analyses are performed in a $10 \mathrm{MW}$ Joule-Brayton PTES system with liquid thermal stores. In this section, the component with the largest irreversibility generation in the system is determined, and the components of the system on which design improvement efforts should focus is illustrated. Finally, an accurate assessment of the performance improvement potential of the system is provided.

\subsection{Results of the conventional exergy analysis}

In this investigation, a complete charge-and-discharge process of the recuperated and non-recuperated Joule-Brayton PTES systems is taken into consideration. The exergy flow and destruction rates of the non-recuperated Joule-Brayton PTES system during the charge-and-discharge process are shown in Fig. 3. During the charge process, the electricity input and output are 59.31 and $17.91 \mathrm{MW}$, respectively, and the net exergy flow rates entering the hot and cold tanks are 23.44 and $3.33 \mathrm{MW}$, respectively. During the discharge process, the net electricity output is $10.00 \mathrm{MW}$, and the net exergy flow rates leaving the hot and cold tanks are 22.38 and $3.04 \mathrm{MW}$, respectively. The exergy flow and destruction rates of the recuperated Joule-Brayton PTES system during the charge-and-discharge process are shown in Fig. 4. During the charge process, the electricity input and output are 57.03 and $14.00 \mathrm{MW}$, respectively, and the net exergy flow rates entering the hot and cold tanks are 29.03 and $1.19 \mathrm{MW}$, respectively. During the discharge process, the net electricity output is $10.0 \mathrm{MW}$, and the net exergy flow rates leaving the hot and cold tanks are 24.57 and $1.14 \mathrm{MW}$, respectively. The exergy flow rate leaving the RCT and entering the CMP during the charge process is $11.21 \mathrm{MW}$, and the exergy flow rate leaving the EXP and entering the RCT during the discharge process is $15.70 \mathrm{MW}$.

The exergy destruction and dissipation rates of the main components in the non-recuperated and recuperated PTES systems are depicted in Fig. 5. For the non-recuperated PTES system, the maximal exergy destruction rate (6.87 MW) occurs within the expander during charge (HP_EXP), the minimal exergy destruction rate (1.02 MW) occurs within the cold heat exchanger during discharge (HE_CHX) and the maximal exergy dissipation rate (6.51 MW) occurs within the auxiliary heat exchangers during discharge (HE_AHX). By comparison, in the recuperated PTES system, the maximal exergy destruction rate $(4.28 \mathrm{MW})$ occurs within the expander during discharge (HE_EXP) and the minimal exergy destruction rate $(0.64 \mathrm{MW})$ occurs within HE_CHX. Moreover, the exergy dissipation rate in the AHXs $(3.10 \mathrm{MW})$ is lower than that in the non-recuperated PTES system. 


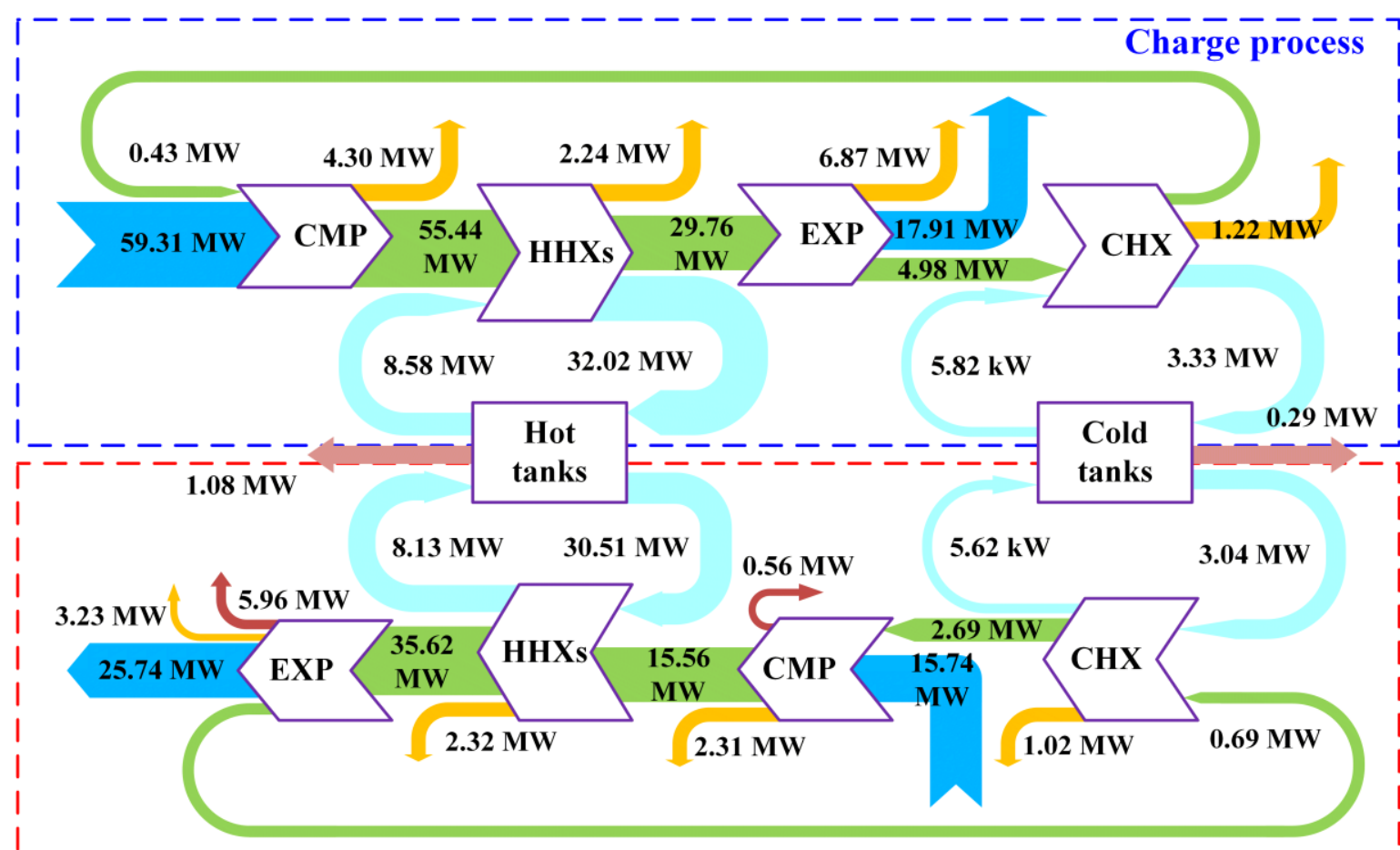

Discharge process I

Electricity input/output

Exergy flow of the working fluid

Exergy flow of the storage liquid

Exergy destruction of the working fluid

Exergy dissipation to the environment

Fig. 3 Diagram of exergy flow and destruction rates of the non-recuperated Joule-Brayton PTES system.

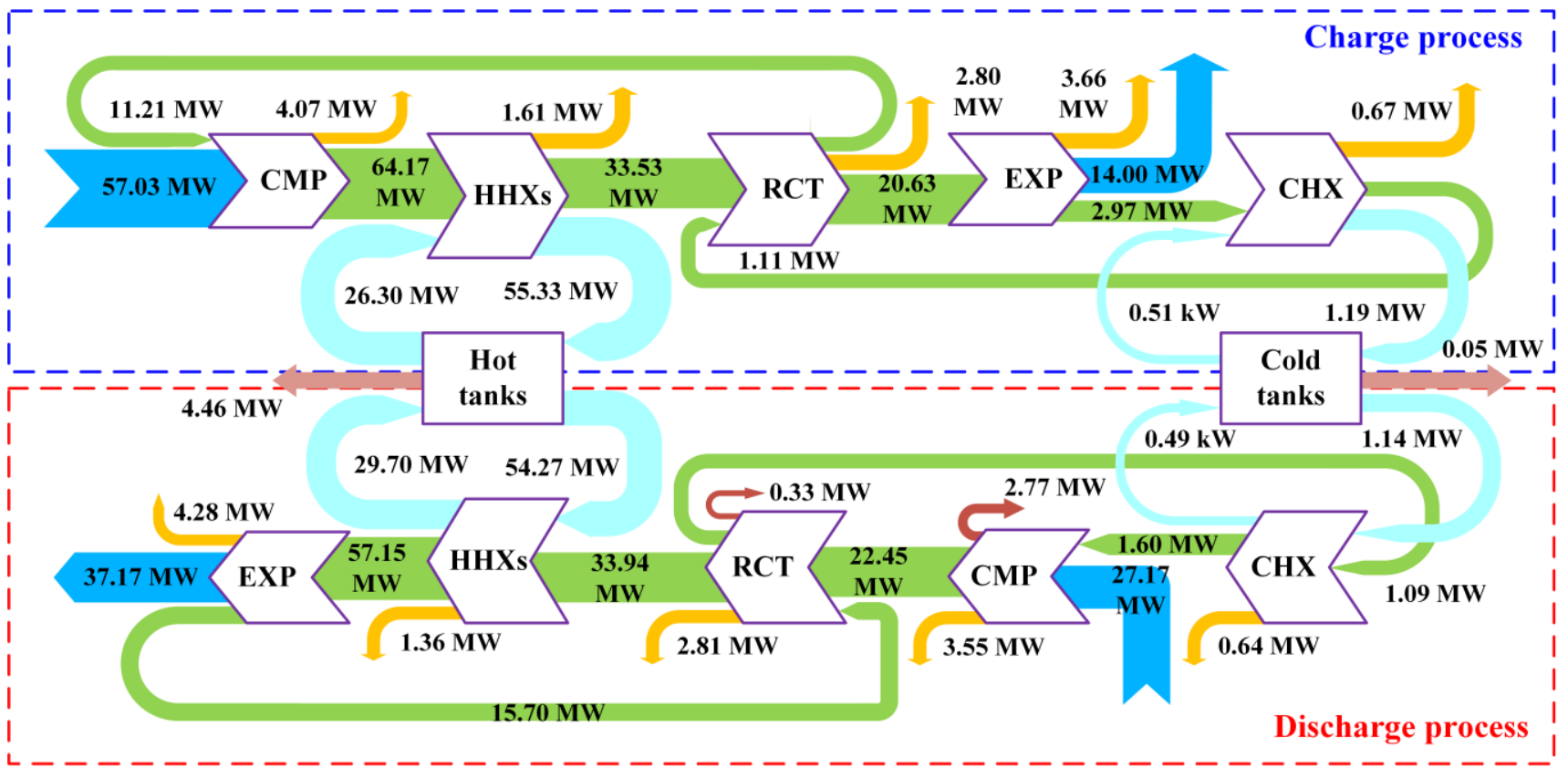

Electricity input/output

Exergy flow of the working fluid

Exergy flow of the storage liquid

Exergy destruction of the working fluid

Exergy dissipation to the environment

Fig. 4 Diagram of exergy flow and destruction rates of the recuperated Joule-Brayton PTES system. 


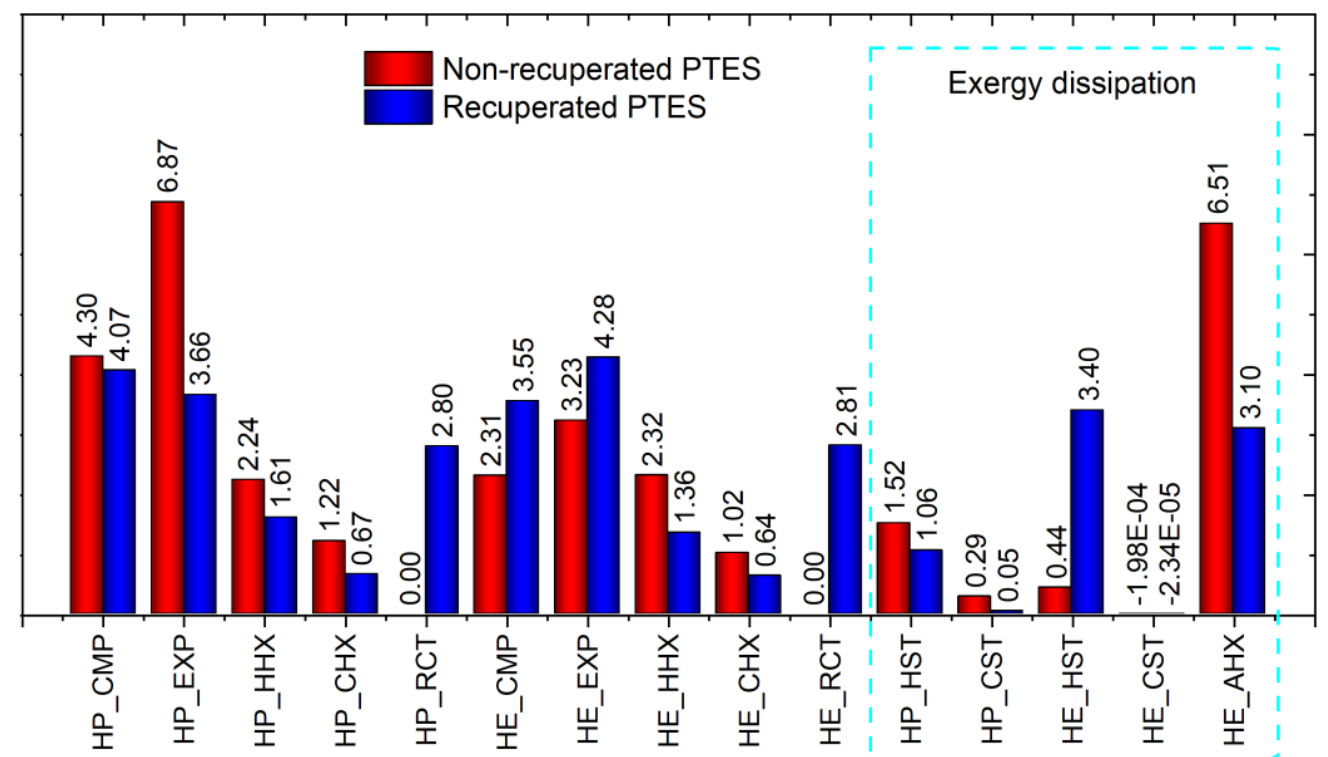

Fig. 5 Exergy destruction and dissipation rates of the main components in the non-recuperated and recuperated PTES systems. Notes: 'HP' and 'HE' represent the charge and discharge processes, respectively.

The initial exergetic efficiencies of the main components in the non-recuperated and recuperated PTES systems are shown in Fig. 6. Except for HP_CHX, HE_CHX and hot thermal stores during discharge (HE_HST), all other components in the recuperated PTES system show higher initial exergetic efficiencies than those in the nonrecuperated PTES system. Fig. 7 shows that relative exergy destruction in the non-recuperated and recuperated PTES systems. In the non-recuperated PTES systems, HP_EXP shows the highest relative exergy destruction (i.e. $21 \%$ of the total exergy destruction rate), followed by HE_AHX (i.e. $20 \%$ of the total exergy destruction rate). In the recuperated PTES system, HE_EXP shows the highest relative exergy destruction rate (i.e. $13 \%$ of the total exergy destruction rate), followed by HP_CMP (i.e. $12 \%$ of the total exergy destruction rate). Considering identical power capacities (10 MW), the relative exergy destruction in the non-recuperated PTES system is higher than that in the recuperated PTES system. This result indicates that adding a RCT can improve the system performance, as expected. Thus, only the recuperated PTES system is considered in the following advanced exergy analysis.

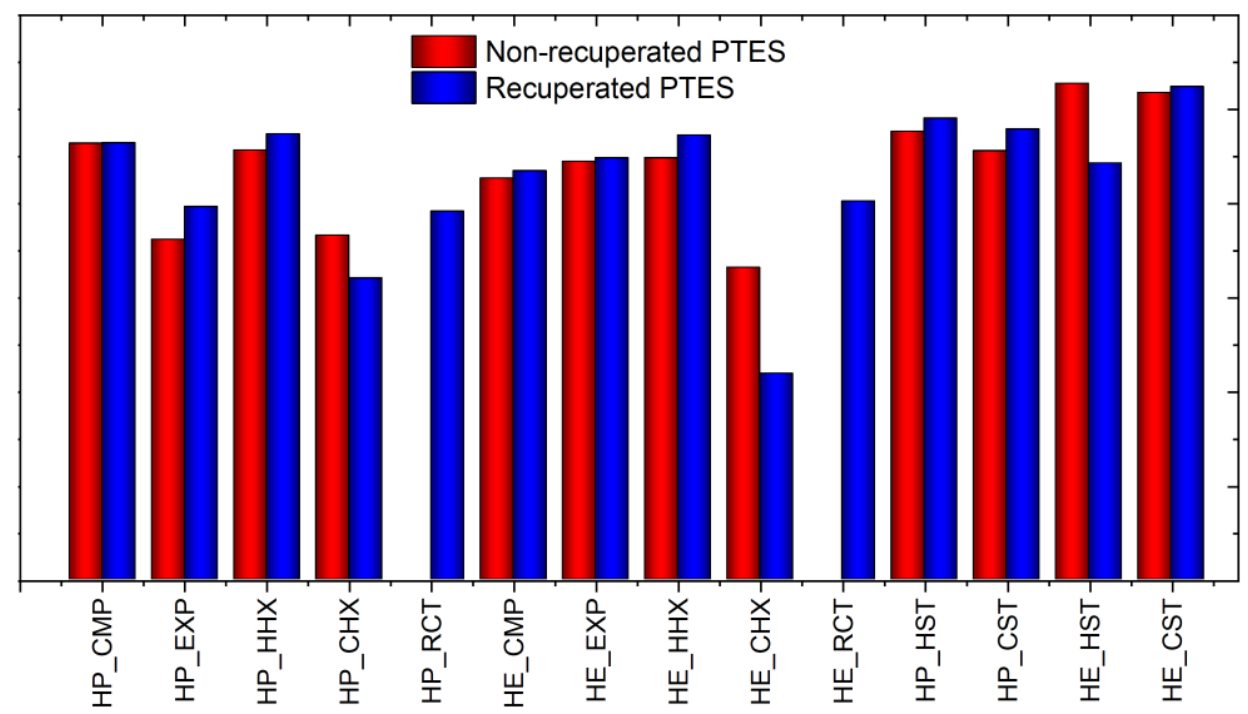

Fig. 6 Initial exergetic efficiencies of the main components in the non-recuperated and recuperated PTES systems. 


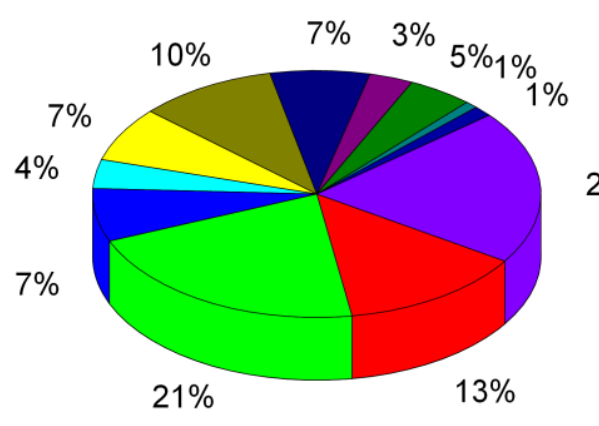

(a) Non-recuperated PTES

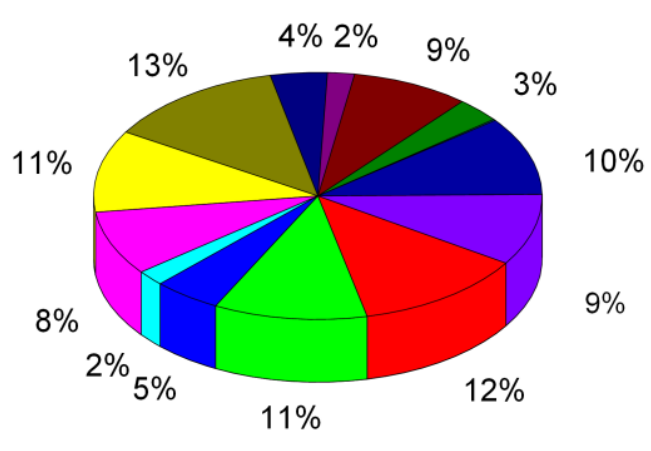

(b) Recuperated PTES

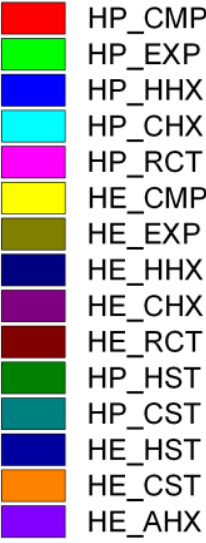

HE_AHX

Fig. 7 Relative exergy destruction of the main components in the non-recuperated and recuperated PTES systems.

\subsection{Results of the advanced exergy analysis}

The advanced exergy analysis described in Section 3.2 is adopted to investigate the recuperated PTES system, and the results are summarised in Table 5. The breakdown of the avoidable and unavoidable exergy destruction rates of the main components of the recuperated PTES system is shown in Fig. 8. HE_CHX has the highest $\dot{E}_{\mathrm{D}}^{\mathrm{AV}}$ (i.e. $95 \%$ of its total exergy destruction rate), and only $5 \%$ of its total exergy destruction rate is unavoidable. By contrast, HP_CMP has the lowest $\dot{E}_{\mathrm{D}}^{\mathrm{AV}}$ (i.e. $50 \%$ of its total exergy destruction rate). The $\dot{E}_{\mathrm{D}}^{\mathrm{AV}}$ values within the CMP and EXP are smaller than those within different heat exchangers (e.g. HHXs, CHX and RCT).

Table 5 Advanced exergy analysis of the main components of the recuperated PTES system (unit: MW).

\begin{tabular}{|c|c|c|c|c|c|c|c|c|c|}
\hline \multirow{2}{*}{ Component } & \multirow{2}{*}{$\dot{E}_{\mathrm{D}, k}$} & \multirow{2}{*}{$\dot{E}_{\mathrm{D}, k}^{\mathrm{UN}}$} & \multirow{2}{*}{$\dot{E}_{\mathrm{D}, k}^{\mathrm{AV}}$} & \multirow{2}{*}{$\dot{E}_{\mathrm{D}, k}^{\mathrm{EN}}$} & \multirow{2}{*}{$\dot{E}_{\mathrm{D}, k}^{\mathrm{EX}}$} & \multicolumn{4}{|c|}{ Splitting $\dot{E}_{\mathrm{D}, k}$} \\
\hline & & & & & & $\dot{E}_{\mathrm{D}, k}^{\mathrm{EN}, \mathrm{UN}}$ & $\dot{E}_{\mathrm{D}, k}^{\mathrm{EN}, \mathrm{AV}}$ & $\dot{E}_{\mathrm{D}, k}^{\mathrm{EX}, \mathrm{UN}}$ & $\dot{E}_{\mathrm{D}, k}^{\mathrm{EX}, \mathrm{AV}}$ \\
\hline HP_CMP & 4.07 & 2.05 & 2.02 & 1.42 & 2.65 & 0.69 & 0.72 & 1.36 & 1.29 \\
\hline HP_EXP & 3.66 & 1.54 & 2.12 & 1.54 & 2.12 & 0.63 & 0.91 & 0.91 & 1.21 \\
\hline HP_HHX & 1.61 & 0.34 & 1.27 & 0.65 & 0.96 & 0.11 & 0.54 & 0.23 & 0.73 \\
\hline HP_CHX & 0.67 & 0.08 & 0.59 & 0.43 & 0.24 & -0.06 & 0.49 & 0.14 & 0.10 \\
\hline HP_RCT & 2.80 & 0.69 & 2.11 & 0.26 & 2.54 & 0.03 & 0.24 & 0.66 & 1.87 \\
\hline HE_CMP & 3.55 & 1.61 & 1.94 & 1.28 & 2.27 & 0.47 & 0.81 & 1.14 & 1.13 \\
\hline HE_EXP & 4.28 & 1.97 & 2.31 & 2.10 & 2.18 & 1.01 & 1.09 & 0.96 & 1.23 \\
\hline HE_HHX & 1.36 & 0.28 & 1.08 & 0.64 & 0.72 & 0.10 & 0.54 & 0.18 & 0.54 \\
\hline HE_CHX & 0.64 & 0.03 & 0.61 & 0.40 & 0.24 & -0.04 & 0.44 & 0.07 & 0.17 \\
\hline HE_RCT & 2.81 & 0.73 & 2.08 & 0.30 & 2.51 & 0.03 & 0.27 & 0.70 & 1.81 \\
\hline
\end{tabular}

The breakdown of endogenous and exogenous exergy destruction rates of the main components of the recuperated PTES system is depicted in Fig. 9. HP_RCT and HE_RCT have the lowest $\dot{E}_{\mathrm{D}}^{\mathrm{EN}}$ (9\%) and the highest $\dot{E}_{\mathrm{D}}^{\mathrm{EX}}(91 \%)$. The $\dot{E}_{\mathrm{D}}^{\mathrm{EN}}$ values of the CMP, EXP and $\mathrm{HHX}$ are consistently less than $50 \%$ of their total exergy destruction rate, which means the interaction between these components is strong. The cold heat exchangers (HP_CHX and HE_CHX) have the highest $\dot{E}_{\mathrm{D}}^{\mathrm{EN}}(63 \%-64 \%)$. 


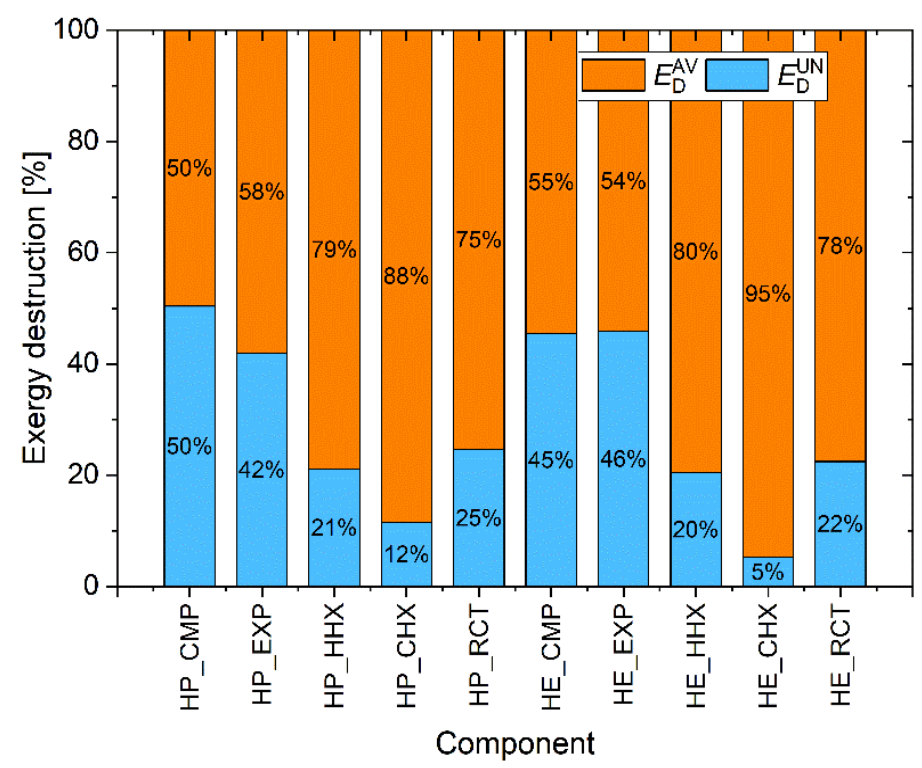

Fig. 8 Breakdown of the avoidable and unavoidable exergy destruction rates of the main components in the recuperated PTES system.

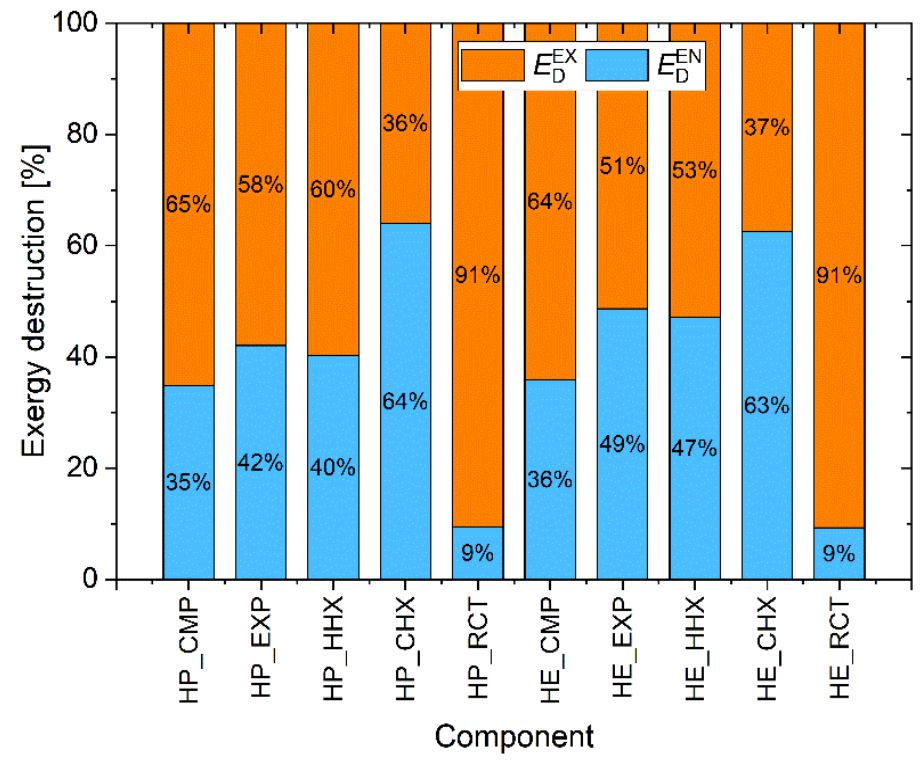

Fig. 9 Breakdown of the endogenous and exogenous exergy destruction rates of the main components in the recuperated PTES system.

The total exergy destruction rate of each component is split into four sub-components, namely the endogenous unavoidable exergy destruction rate, the endogenous avoidable exergy destruction rate, the exogenous unavoidable exergy destruction rate and the exogenous avoidable exergy destruction rate, based on Eqs. (26)-(33). Fig. 10 shows the breakdown of the total exergy destruction rate of the main components of the recuperated PTES system. For HP_CMP and HE_CMP, the largest exergy destruction rate is $\dot{E}_{\mathrm{D}}^{\mathrm{EX}, \mathrm{UN}}$, followed by $\dot{E}_{\mathrm{D}}^{\mathrm{EX}, \mathrm{AV}}$ and the smallest exergy destruction rate is $\dot{E}_{\mathrm{D}}^{\mathrm{EN}, \mathrm{UN}}$. For HP_EXP and HE_EXP, the largest exergy destruction rate is $\dot{E}_{\mathrm{D}}^{\mathrm{EX}, \mathrm{AV}}$, followed by $\dot{E}_{\mathrm{D}}^{\mathrm{EN}, \mathrm{AV}}$ and the smallest exergy destruction rate is $\dot{E}_{\mathrm{D}}^{\mathrm{EN}, \mathrm{UN}}$. For HP_HHX and HE_HHX, $\dot{E}_{\mathrm{D}}^{\mathrm{EX}, \mathrm{AV}}$ and $\dot{E}_{\mathrm{D}}^{\mathrm{EN}, \mathrm{AV}}$ contribute the most to the exergy destruction rate, whilst $\dot{E}_{\mathrm{D}}^{\mathrm{EN}, \mathrm{UN}}$ and $\dot{E}_{\mathrm{D}}^{\mathrm{EX}, \mathrm{UN}}$ contribute the least. For $\mathrm{HP} \_\mathrm{CHX}$ and $\mathrm{HE} \_\mathrm{CHX}$, the main contributor of the exergy destruction rate is $\dot{E}_{\mathrm{D}}^{\mathrm{EN}, \mathrm{AV}}$; the other sub-components contribute minimally to this rate. For HP_RCT and HE_RCT, the largest contributors to the exergy destruction rate are $\dot{E}_{\mathrm{D}}^{\mathrm{EX}, \mathrm{AV}}$ and $\dot{E}_{\mathrm{D}}^{\mathrm{EX}, \mathrm{UN}}$, and the smallest contributor is $\dot{E}_{\mathrm{D}}^{\mathrm{EN}, \mathrm{UN}}$. Most of the exergy destruction rates within the CMPs, EXPs and RCTs are exogenously avoidable and unavoidable. The largest $\dot{E}_{\mathrm{D}}^{\mathrm{EX}, \mathrm{AV}}$ and $\dot{E}_{\mathrm{D}}^{\mathrm{EX}, \mathrm{UN}}$ come from the RCTs 
and CMPs, respectively, and the largest $\dot{E}_{\mathrm{D}}^{\mathrm{EN}, \mathrm{AV}}$ and $\dot{E}_{\mathrm{D}}^{\mathrm{EN}, \mathrm{UN}}$ come from HE_EXP.

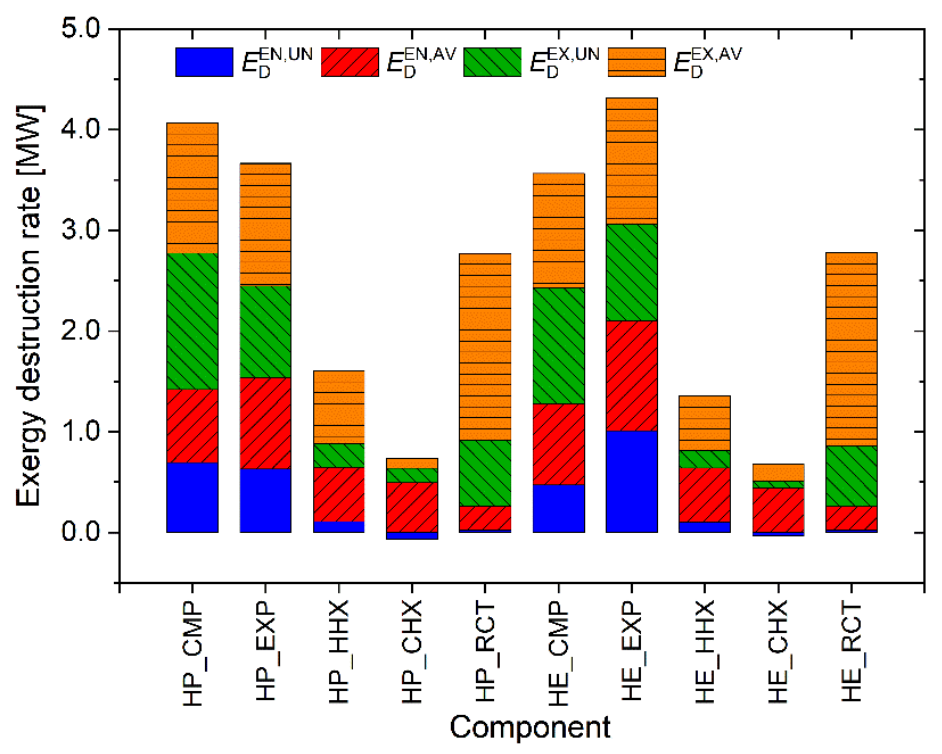

Fig. 10 Breakdown of the total exergy destruction rate of the main components in the recuperated PTES system.

A comparison of the initial and modified exergetic efficiencies of the main components of the PTES system, which defined according to Eqs. (20) and (32), respectively, is shown in Fig. 11. CHXs have the largest improvement potential in terms of the exergetic efficiency (HP_CHX: from $64 \%$ to $94 \%$; HE_CHX: from $44 \%$ to 94\%), followed by RCTs (HP_RCT: from $78 \%$ to $94 \%$; HE_RCT: from $80 \%$ to $95 \%$ ) and EXPs (HP_EXP: from $79 \%$ to $90 \%$; HE_EXP: from $90 \%$ to $95 \%$ ). CMPs and HHXs have the smallest improvement potential in terms of the exergetic efficiency (i.e. $<7 \%$ ).

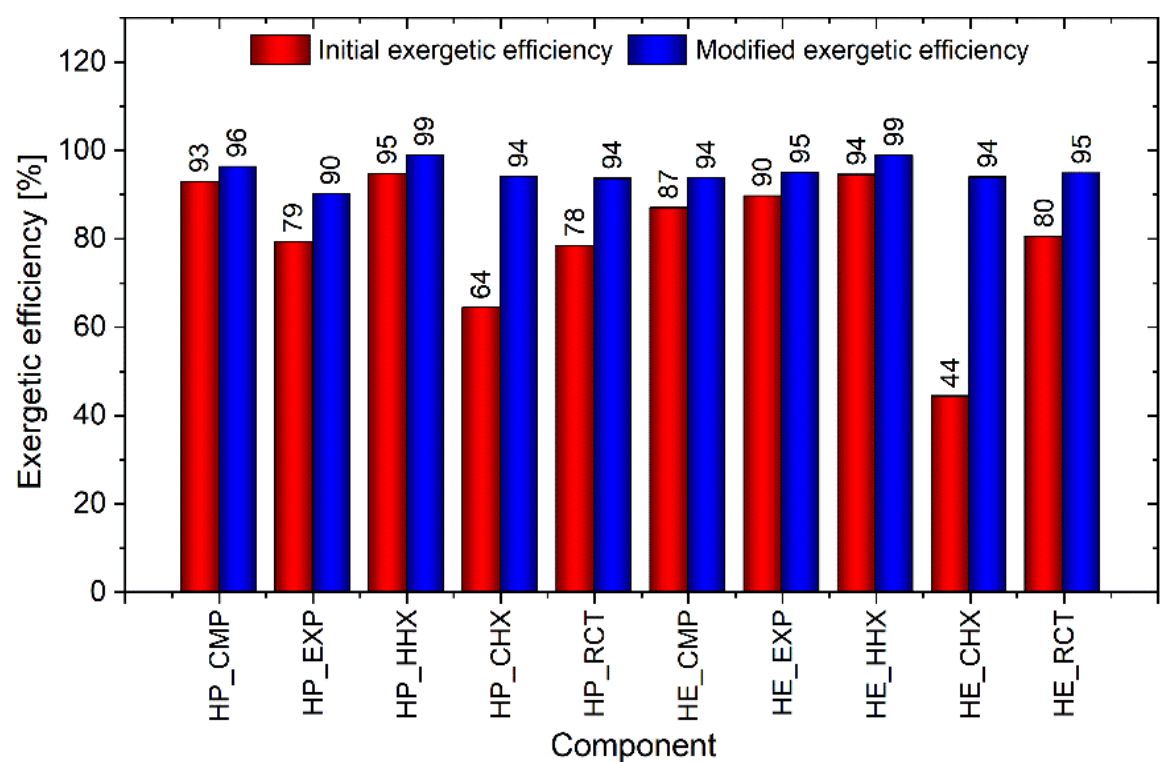

Fig. 11 Comparison of the initial and modified exergetic efficiencies of the main components in the recuperated PTES system. These exergetic efficiencies are defined according to Eqs. (20) and (32), respectively.

\subsection{Quantitative analysis of performance improvement potential}

The component with the largest irreversibility generation in the recuperated PTES system is identified and the components on which design improvement efforts should focus are determined from the results of conventional and advanced exergy analyses. In the following investigation, a quantitative analysis of the performance improvement 
potential of the PTES system is performed. Here, four parameters are taken into consideration, including the isentropic efficiencies of the CMP and EXP, and the effectiveness and pressure loss factor of all heat exchangers.

\subsubsection{Effects of turbomachines}

Isentropic efficiency is a key parameter that can reflect the technological readiness level of a CMP and EXP. The effects of the isentropic efficiency of the CMP on the distinct exergy destruction rates are shown in Fig. 12. Increasing the isentropic efficiency of the CMP sharply decreases $\dot{E}_{\mathrm{D}}^{\mathrm{EN}, \mathrm{AV}}$ within HP_CMP and HE_CMP, minimally decreases $\dot{E}_{\mathrm{D}}^{\mathrm{EN}, \mathrm{UN}}$ within HP_CMP and HE_CMP and has negligible effects on $\dot{E}_{\mathrm{D}}^{\mathrm{EN}, \mathrm{UN}}$ and $\dot{E}_{\mathrm{D}}^{\mathrm{EN}, \mathrm{AV}}$ within other components. In addition, $\dot{E}_{\mathrm{D}}^{\mathrm{EX}, \mathrm{UN}}$ and $\dot{E}_{\mathrm{D}}^{\mathrm{EX}, \mathrm{AV}}$ within the CMPs, EXPs and RCTs gradually decrease with increasing the isentropic efficiency, especially in the CMPs. Increases of isentropic efficiency have a negligible influence on the $\dot{E}_{\mathrm{D}}^{\mathrm{EX}, \mathrm{UN}}$ and $\dot{E}_{\mathrm{D}}^{\mathrm{EX}, \mathrm{AV}}$ of the $\mathrm{HHXs}$ and $\mathrm{CHXs}$.
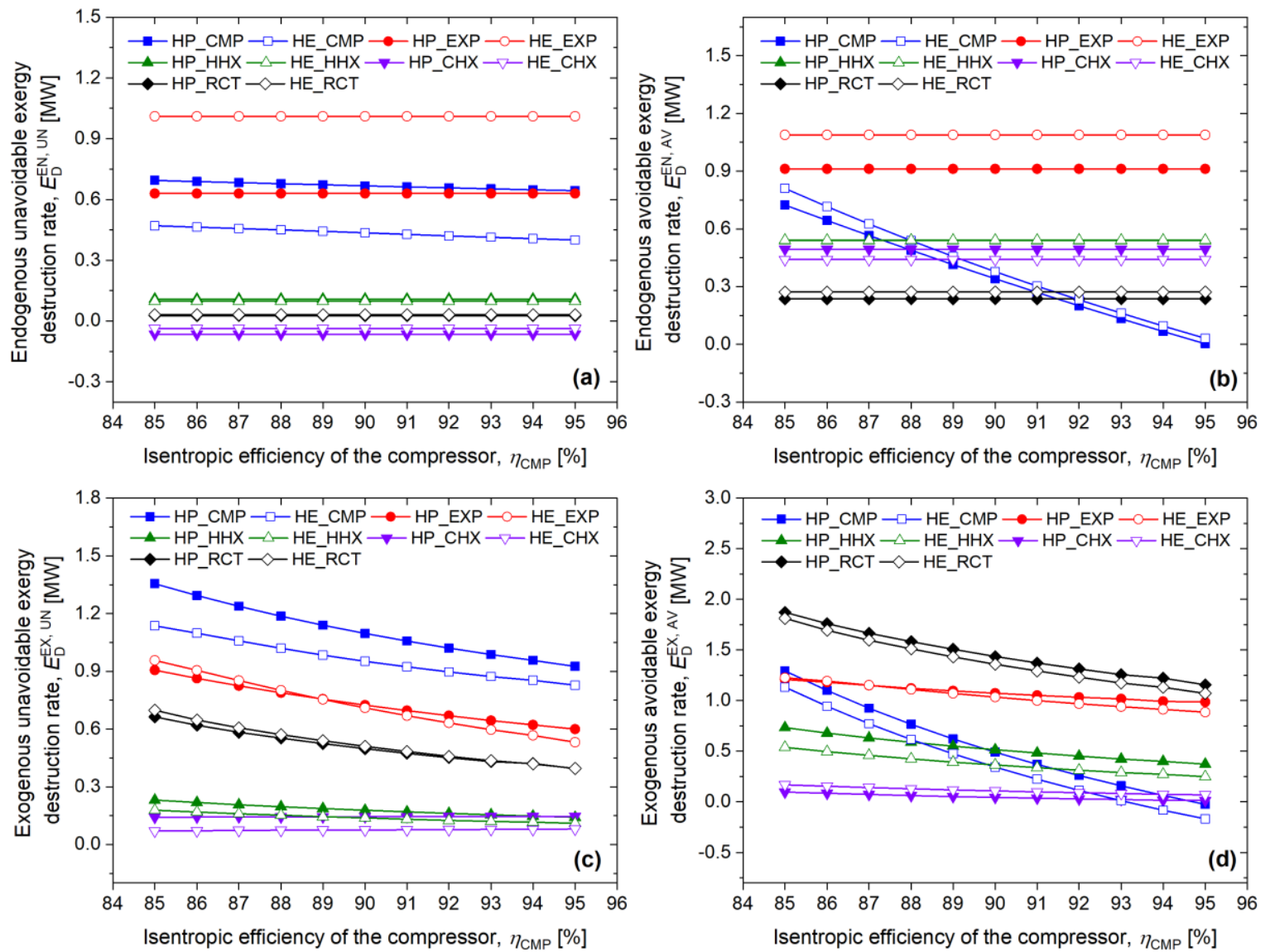

Fig. 12 Effects of the isentropic efficiency of the compressor on the distinct exergy destruction rates in the recuperated PTES system: (a) the endogenous unavoidable rate, (b) the endogenous avoidable rate, (c) the exogenous unavoidable rate and (d) the exogenous avoidable rate.

The effects of the isentropic efficiency of the EXP on the distinct exergy destruction rates are shown in Fig. 13. Increasing the isentropic efficiency of the EXP sharply decreases $\dot{E}_{\mathrm{D}}^{\mathrm{EN}, \mathrm{AV}}$ within HP_EXP and HE_EXP, slightly decreases $\dot{E}_{\mathrm{D}}^{\mathrm{EN}, \mathrm{UN}}$ within HP_EXP and HE_EXP but does not affect $\dot{E}_{\mathrm{D}}^{\mathrm{EN}, \mathrm{UN}}$ and $\dot{E}_{\mathrm{D}}^{\mathrm{EN}, \mathrm{AV}}$ within other components. In addition, $\dot{E}_{\mathrm{D}}^{\mathrm{EX}, \mathrm{UN}}$ and $\dot{E}_{\mathrm{D}}^{\mathrm{EX}, \mathrm{AV}}$ within the CMPs, EXPs and RCTs gradually decrease with increasing isentropic efficiency. In the HHXs, increasing isentropic efficiency slightly decreases $\dot{E}_{\mathrm{D}}^{\mathrm{EX}, \mathrm{AV}}$ but does not affect $\dot{E}_{\mathrm{D}}^{\mathrm{EX}, \mathrm{UN}}$. In the $\mathrm{CHXs}$, increasing isentropic efficiency has a negligible effect on $\dot{E}_{\mathrm{D}}^{\mathrm{EX}, \mathrm{UN}}$ and $\dot{E}_{\mathrm{D}}^{\mathrm{EX}, \mathrm{AV}}$.

The effects of the isentropic efficiency of the turbomachines on the original and modified overall exergetic efficiencies, which are defined according to Eqs. (21) and (33), respectively, are shown in Fig. 14. Increasing the isentropic efficiency of the CMP and EXP from $85 \%$ to $95 \%$ increases the original overall exergetic efficiency by $25 \%$ 
(from $23 \%$ to $48 \%$ ) and the modified overall exergetic efficiency by $20 \%$ (from $37 \%$ to $57 \%$ ). These results indicate that improving the technological readiness level of turbomachines can increase the overall exergetic efficiency of the PTES system by up to $57 \%$. Compared with that of the CMP, increasing the isentropic efficiency of the EXP has a more sensitive effect on the original and modified overall exergetic efficiencies.
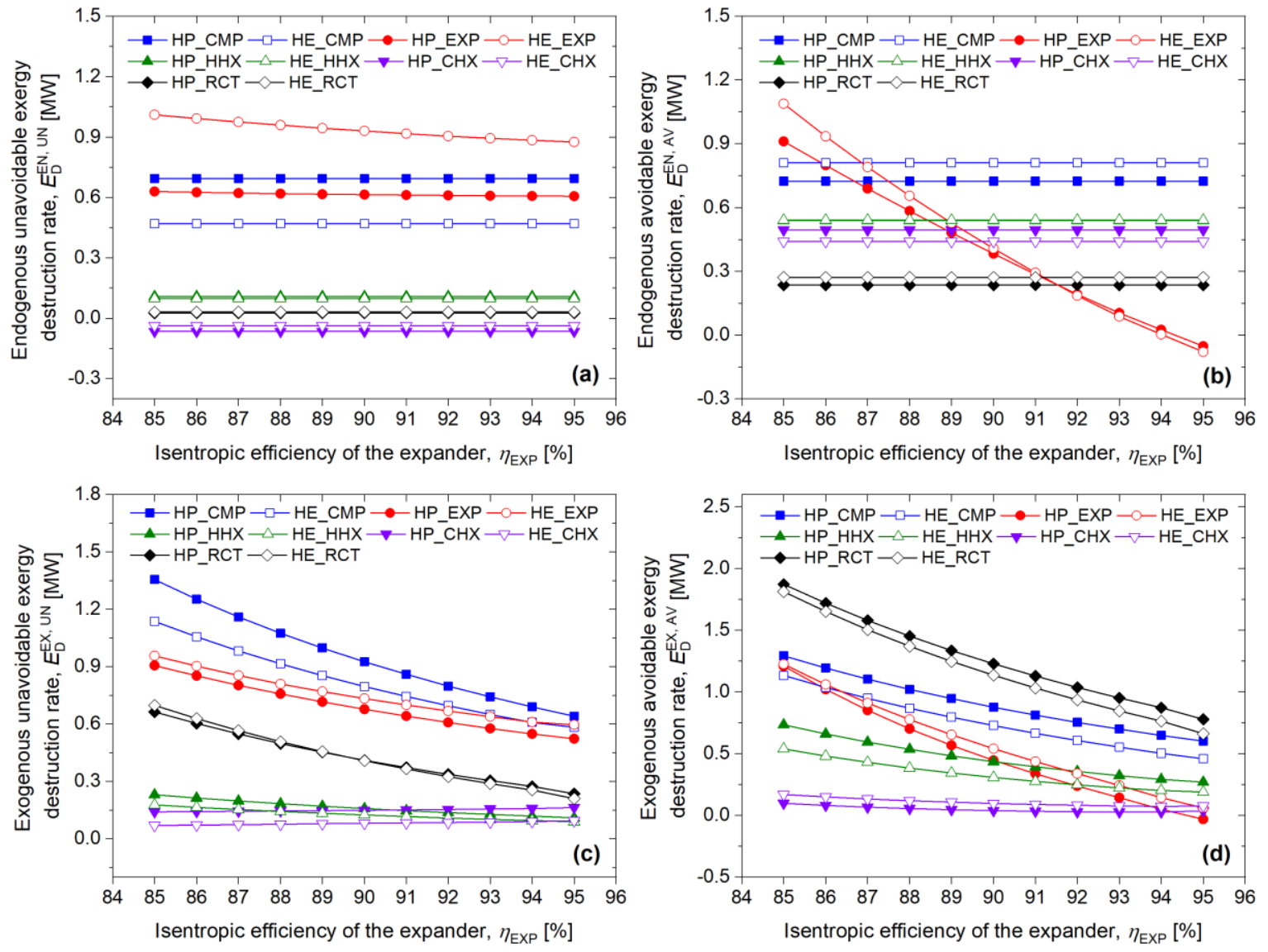

Fig. 13 Effects of the isentropic efficiency of the EXP on the distinct exergy destruction rates in the recuperated PTES system: (a) the endogenous unavoidable rate, (b) the endogenous avoidable rate, (c) the exogenous unavoidable rate and (d) the exogenous avoidable rate.

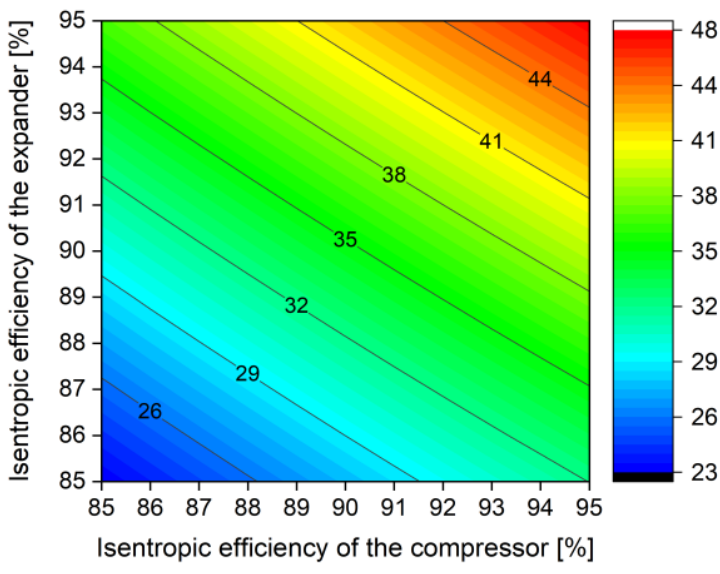

(a) Original overall exergetic efficiency

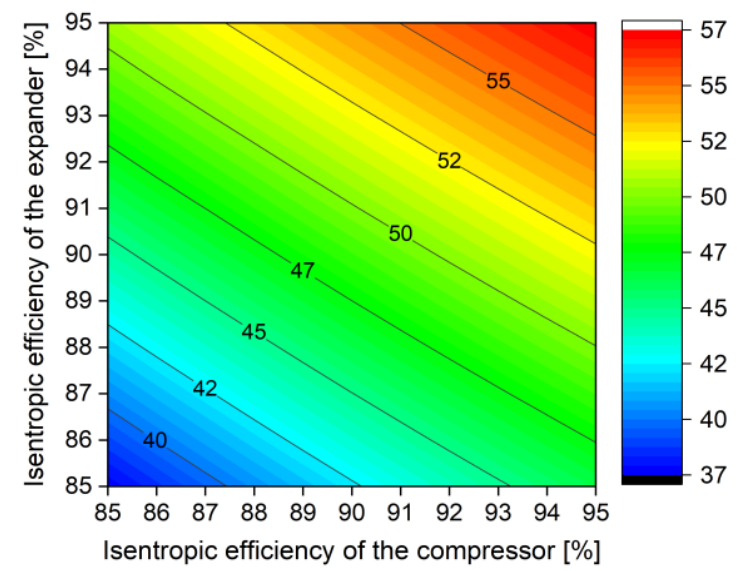

(b) Modified overall exergetic efficiency

Fig. 14 Effects of the isentropic efficiency of the turbomachines on the PTES system performance: (a) the original overall exergetic efficiency and (b) the modified overall exergetic efficiency. 


\subsubsection{Effects of heat exchangers}

The effectiveness and pressure loss factor are two key parameters that influencing the technological readiness level of a heat exchanger. Changes in exergy destruction rates obtained by varying the effectiveness of all heat exchangers (HHXs, CHXs and RCTs) are investigated, as shown in Fig. 15. The results illustrate that increasing the effectiveness of all heat exchangers sharply decreases $\dot{E}_{\mathrm{D}}^{\mathrm{EN}, \mathrm{AV}}$ within the $\mathrm{HHXs}$ and $\mathrm{CHXs}$, slightly decreases the $\dot{E}_{\mathrm{D}}^{\mathrm{EN}, \mathrm{UN}}$ of the $\mathrm{HHXs}$ and $\mathrm{CHXs}$ but does not affect $\dot{E}_{\mathrm{D}}^{\mathrm{EN}, \mathrm{UN}}$ and $\dot{E}_{\mathrm{D}}^{\mathrm{EN}, \mathrm{AV}}$ within other components. In addition, $\dot{E}_{\mathrm{D}}^{\mathrm{EX}, \mathrm{UN}}$ and $\dot{E}_{\mathrm{D}}^{\mathrm{EX}, \mathrm{AV}}$ within the CMPs and EXPs gradually decrease with increasing effectiveness. Increasing effectiveness causes $\dot{E}_{\mathrm{D}}^{\mathrm{EX}, \mathrm{AV}}$ to decrease and $\dot{E}_{\mathrm{D}}^{\mathrm{EX}, \mathrm{UN}}$ to increase in RCTs but has a negligible influence on $\dot{E}_{\mathrm{D}}^{\mathrm{EX}, \mathrm{UN}}$ and $\dot{E}_{\mathrm{D}}^{\mathrm{EX}, \mathrm{AV}}$ in the $\mathrm{HHXs}$ and $\mathrm{CHXs}$.
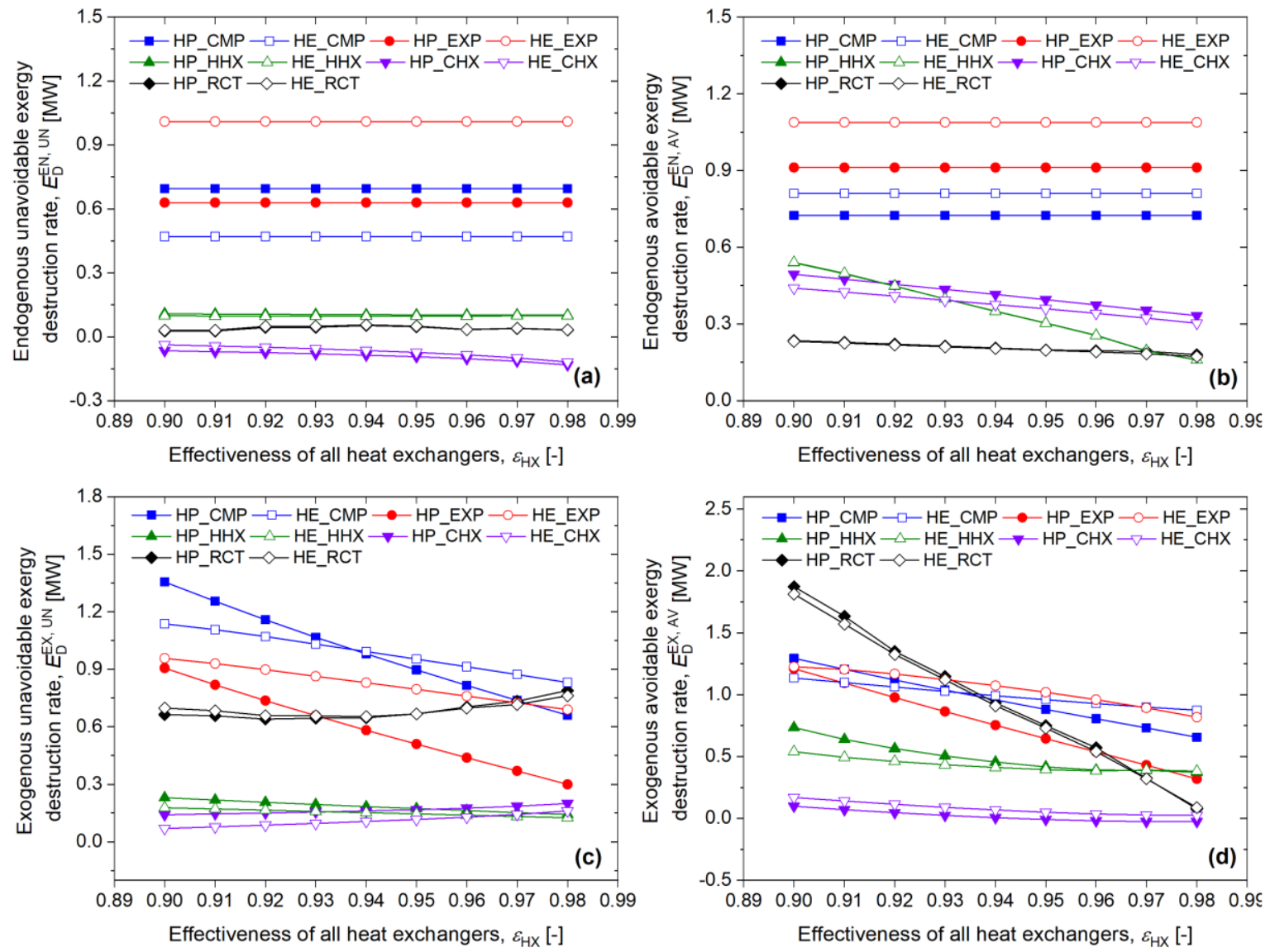

Fig. 15 Effects of the effectiveness of all heat exchangers on the distinct exergy destruction rates in the recuperated PTES system: (a) the endogenous unavoidable rate, (b) the endogenous avoidable rate, (c) the exogenous unavoidable rate and (d) the exogenous avoidable rate.

The effects of the pressure loss factor of all heat exchangers (HHXs, CHXs and RCTs) on the distinct exergy destruction rates are depicted in Fig. 16. When the pressure loss factor of all heat exchangers is increased, $\dot{E}_{\mathrm{D}}^{\mathrm{EN}, \mathrm{UN}}$ within all components is not affected; $\dot{E}_{\mathrm{D}}^{\mathrm{EN}, \mathrm{AV}}$ within the HHXs, CHXs and RCTs sharply increases; and $\dot{E}_{\mathrm{D}}^{\mathrm{EN}, \mathrm{AV}}$ within the CMPs and EXPs is stably maintained. Moreover, $\dot{E}_{\mathrm{D}}^{\mathrm{EX}, \mathrm{UN}}$ and $\dot{E}_{\mathrm{D}}^{\mathrm{EX}, \mathrm{AV}}$ within all components increase when the pressure loss factor of all heat exchangers is increased, and the increment of these exergy destruction rates within CMPs, EXPs and RCTs are larger than that within HHXs and CHXs.

The effects of the effectiveness and pressure loss factor of all heat exchangers on the original and modified overall exergetic efficiencies are shown in Fig. 17. The results illustrate that the original overall exergetic efficiency increases by $23 \%$ (from $21 \%$ to $44 \%$ ) and the modified overall exergetic efficiency increases by $20 \%$ (from $34 \%$ to $54 \%$ ) when the effectiveness of all heat exchangers is increased from 0.90 to 0.98 and the pressure loss factor of all heat 
exchangers is decreased from $2.5 \%$ to $0.5 \%$. This result indicates that improving the technological readiness level of all heat exchangers (i.e. increasing their effectiveness and decreasing their pressure loss factor) can increase the overall exergetic efficiency of the PTES system by up to $54 \%$.

In summary, key parameters related to turbomachines and heat exchangers of a PTES system are optimised, and the overall system performance improvement potential of the recuperated PTES system is evaluated, which can provide valuable guidance for the future design, development and industrial applications of PTES technology.
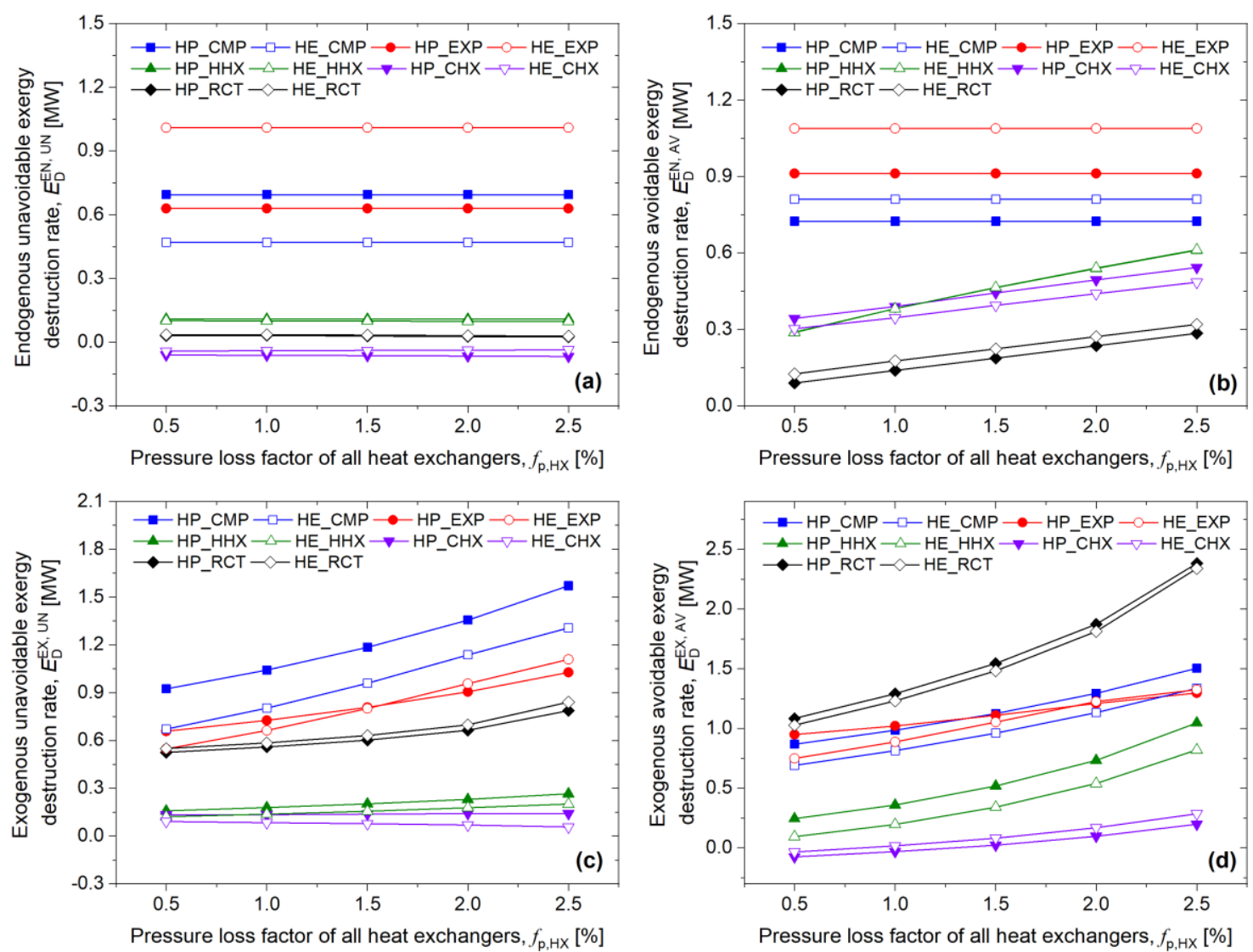

Fig. 16 Effects of the pressure loss factor of all heat exchangers on the distinct exergy destruction rates in the recuperated PTES system: (a) the endogenous unavoidable rate, (b) the endogenous avoidable rate, (c) the exogenous unavoidable rate and (d) the exogenous avoidable rate.

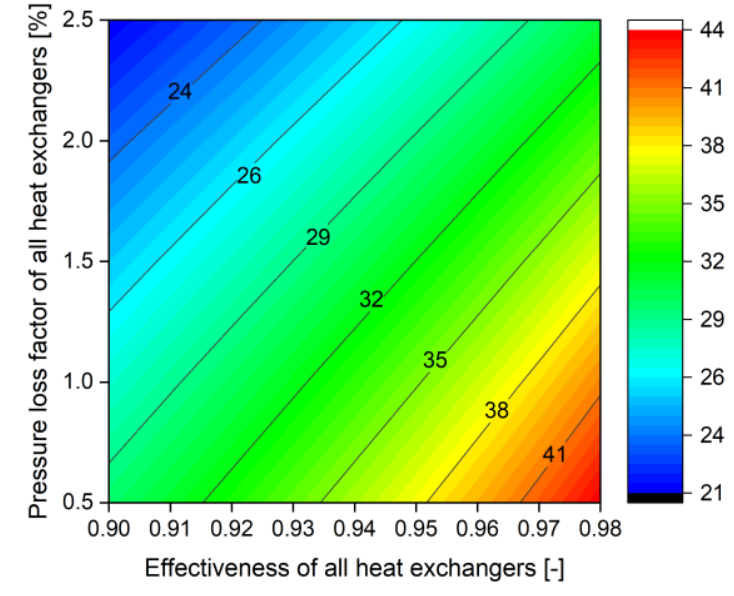

(a) Original overall exergetic efficiency

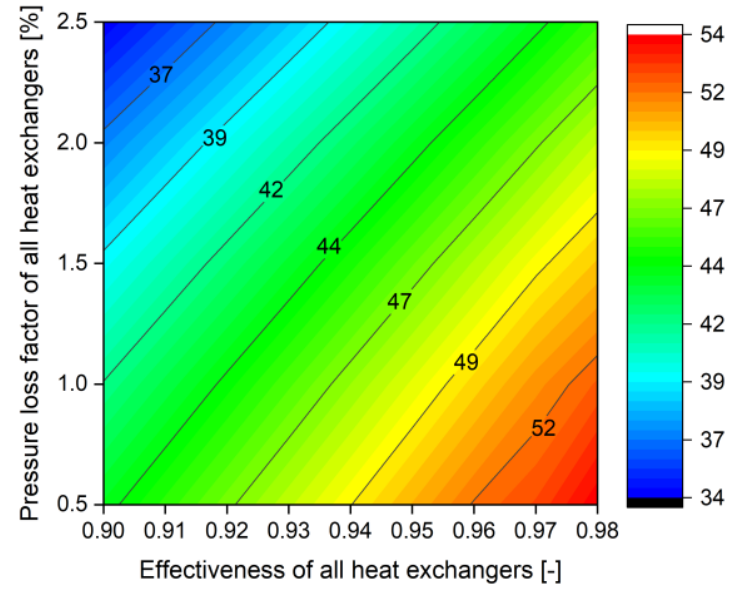

(b) Modified overall exergetic efficiency

Fig. 17 Effects of the effectiveness and pressure loss factor of all heat exchangers on the PTES system performance: (a) the original overall exergetic efficiency and (b) the modified overall exergetic efficiency. 


\section{Conclusions}

Pumped thermal electricity storage (PTES) is a thermo-mechanical energy storage technology that has emerged as a promising option for large-scale storage as it promises as a lack of geographical restrictions, relatively low capital costs and long lifetime, and is considered as one of the more promising solutions for grid-scale/bulk storage in future electrical power systems. This paper focuses on a $10 \mathrm{MW}$ Joule-Brayton PTES system with liquid thermal stores and performs detailed conventional and advanced exergy analyses of this system in an attempts to fill a gap in the literature by identifying the component(s) with the largest irreversibility, determining the components that should be at the focal point of concentrated design improvement efforts, and quantifying of the efficiency improvement potential that can result from these component improvements at the technology level.

A conventional exergy analysis was performed on both non-recuperated and recuperated PTES system variants after validating the thermodynamic models and exergy analysis methods. It was found that in the non-recuperated PTES system, the maximum exergy destruction rate (6.87 MW) occurs in the expander during charge, and accounts for $21 \%$ of the total exergy destruction rate. The maximum exergy destruction rate $(4.28 \mathrm{MW})$ in the recuperated system occurs in the expander during discharge, and accounts for $13 \%$ of the total exergy destruction rate. Except for the cold heat exchanger and the hot storage tank, other components in the recuperated PTES system all have higher initial exergetic efficiencies than those in the corresponding non-recuperated system.

An advanced exergy analysis was also performed on the recuperated PTES system. This analysis revealed that the cold heat exchanger during discharge and the compressor during charge achieve the highest share (95\%) and the lowest share $(50 \%)$ of avoidable exergy destruction rate, respectively, and also that the cold heat exchanger during charge and the recuperator during charge or discharge obtain the highest share $(64 \%)$ and the lowest share $(9 \%)$ of endogenous exergy destruction rates, respectively. Moreover, the interaction among the main components is strong because most of exergy destruction rates within the compressor, expander and recuperator are exogenous; amongst all components, the largest exogenous and endogenous avoidable exergy destruction rates arise in the recuperator and expander, respectively. Furthermore, the cold heat exchanger has the largest potential for exergetic efficiency improvement, followed by the recuperator and expander.

Finally, a quantitative analysis of the overall performance improvement potential of the recuperated PTES system was performed, which considered four key parameters relating to the operation and performance of the turbomachines and heat exchangers. Increasing the isentropic efficiency of the compressor and expander from $85 \%$ to $95 \%$ increases the original overall exergetic efficiency by $25 \%$ (from $23 \%$ to $48 \%$ ) and the modified overall exergetic efficiency by $20 \%$ (from $37 \%$ to $57 \%$ ). Compared with that of the compressor, increasing the isentropic efficiency of the expander has a sensitive effect on the original and modified overall exergetic efficiencies. Moreover, the original overall exergetic efficiency increases by $23 \%$ (from $21 \%$ to $44 \%$ ) and the modified overall exergetic efficiency increases by $20 \%$ (from $34 \%$ to $54 \%$ ) when the effectiveness of all heat exchangers is increased from 0.90 to 0.98 and the pressure loss factor of all heat exchangers is decreased from $2.5 \%$ to $0.5 \%$.

\section{Acknowledgement}

This work was supported by the Basic Science Centre Program for Ordered Energy Conversion of the National Natural Science Foundation of China (No. 51888103), and the China Scholarship Council for a joint-PhD scholarship (No. 201906280328) that supported Yongliang Zhao's visit to Imperial College London. This work was also supported by the UK Engineering and Physical Sciences Research Council (EPSRC) [grant numbers EP/S032622/1 and EP/R045518/1]. Data supporting this publication can be obtained on request from cep-lab@ imperial.ac.uk. 


\section{References}

[1] Zappa W, Junginger M, van den Broek M. Is a $100 \%$ renewable European power system feasible by 2050 ? Applied Energy 2019;233-234:1027-1050. https://doi.org/10.1016/i.apenergy.2018.08.109.

[2] Lu X, McElroy MB, Peng W, Liu SY, Nielsen CP, Wang HK. Challenges faced by China compared with the US in developing wind power. Nature energy 2016;1:1-6. http://dx.doi.org/10.1038/nenergy.2016.61.

[3] Liu H, He Q, Borgia A, Pan L, Oldenburg CM. Thermodynamic analysis of a compressed carbon dioxide energy storage system using two saline aquifers at different depths as storage reservoirs. Energy Conversion and Management 2016;127:149-159. http://dx.doi.org/10.1016/i.enconman.2016.08.096.

[4] Ulbig A, Andersson G. Analyzing operational flexibility of electric power systems. International Journal of Electrical Power \& Energy Systems 2015;72:155-164. http://dx.doi.org/10.1016/i.ijepes.2015.02.028.

[5] Abdin IF, Zio E. An integrated framework for operational flexibility assessment in multi-period power system planning with renewable energy production. Applied Energy 2018;222:898-914. http://dx.doi.org/10.1016/i.apenergy.2018.04.009.

[6] Pavic I, Capuder T, Kuzle I. Low carbon technologies as providers of operational flexibility in future power systems. Applied Energy 2016;168:724-738. http://dx.doi.org/10.1016/i.apenergy.2016.01.123.

[7] Cruz MRM, Fitiwi DZ, Santos SF, Catalão JPS. A comprehensive survey of flexibility options for supporting the low-carbon energy future. Renewable and Sustainable Energy Reviews 2018;97:338-353. https://doi.org/10.1016/j.rser.2018.08.028.

[8] Zhao YL, Wang CY, Liu M, Chong DT, Yan JJ. Improving operational flexibility by regulating extraction steam of high-pressure heaters on a $660 \mathrm{MW}$ supercritical coal-fired power plant: A dynamic simulation. Applied Energy 2018;212:1295-1309. https://doi.org/10.1016/j.apenergy.2018.01.017.

[9] Lund PD, Lindgren J, Mikkola J, Salpakari J. Review of energy system flexibility measures to enable high levels of variable renewable electricity. Renewable and Sustainable Energy Reviews 2015;45:785-807. http://dx.doi.org/10.1016/j.rser.2015.01.057.

[10] Gonzalez-Salazar MA, Kirsten T, Prchlik L. Review of the operational flexibility and emissions of gas- and coal-fired power plants in a future with growing renewables. Renewable and Sustainable Energy Reviews 2018;82:1497-1513. http://dx.doi.org/10.1016/j.rser.2017.05.278.

[11] Liu R, Liu M, Zhao Y, Ma Y, Yan J. Thermodynamic study of a novel lignite poly-generation system driven by solar energy. Energy 2021;214. https://doi.org/10.1016/j.energy.2020.119075.

[12] Zhao YL, Liu M, Wang CY, Li X, Chong DT, Yan JJ. Increasing operational flexibility of supercritical coal-fired power plants by regulating thermal system configuration during transient processes. Applied Energy 2018;228:2375-2386. https://doi.org/10.1016/j.apenergy.2018.07.070.

[13] Wang CY, Zhao YL, Liu M, Qiao YQ, Chong DT, Yan JJ. Peak shaving operational optimization of supercritical coal-fired power plants by revising control strategy for water-fuel ratio. Applied Energy 2018;216:212-223. https://doi.org/10.1016/j.apenergy.2018.02.039.

[14] Razmara M, Bharati GR, Hanover D, Shahbakhti M, Paudyal S, Robinett RD, III. Building-to-grid predictive power flow control for demand response and demand flexibility programs. Applied Energy 2017;203:128-141. http://dx.doi.org/10.1016/j.apenergy.2017.06.040.

[15] Hadjipaschalis I, Poullikkas A, Efthimiou V. Overview of current and future energy storage technologies for electric power applications. Renewable and Sustainable Energy Reviews 2009;13(6-7):1513-1522. https://doi.org/10.1016/j.rser.2008.09.028.

[16] Luo X, Wang JH, Dooner M, Clarke J. Overview of current development in electrical energy storage technologies and the application potential in power system operation. Applied Energy 2015;137:511-536. http://dx.doi.org/10.1016/i.apenergy.2014.09.081.

[17] Hameer S, van Niekerk JL. A review of large-scale electrical energy storage. International Journal of Energy 
Research 2015;39(9):1179-1195. https://doi.org/10.1002/er.3294.

[18] He W, Wang JH. Optimal selection of air expansion machine in compressed air energy storage: A review. Renewable \& Sustainable Energy Reviews 2018;87:77-95. https://doi.org/10.1016/j.rser.2018.01.013.

[19] Roushenas R, Razmi AR, Soltani M, Torabi M, Dusseault MB, Nathwani J. Thermo-environmental analysis of a novel cogeneration system based on solid oxide fuel cell (SOFC) and compressed air energy storage (CAES) coupled with turbocharger. Applied Thermal Engineering 2020;181. https://doi.org/10.1016/i.applthermaleng.2020.115978.

[20] Soltani M, Nabat MH, Razmi AR, Dusseault MB, Nathwani J. A comparative study between ORC and Kalina based waste heat recovery cycles applied to a green compressed air energy storage (CAES) system. Energy Conversion and Management 2020;222. https://doi.org/10.1016/j.enconman.2020.113203.

[21] Ferreira HL, Garde R, Fulli G, Kling W, Lopes JP. Characterisation of electrical energy storage technologies. Energy 2013;53:288-298. https://doi.org/10.1016/j.energy.2013.02.037.

[22] Lee I, You FQ. Systems design and analysis of liquid air energy storage from liquefied natural gas cold energy. Applied Energy 2019;242:168-180. https://doi.org/10.1016/i.apenergy.2019.03.087.

[23] Benato A, Stoppato A. Pumped thermal electricity storage: A technology overview. Thermal Science and Engineering Progress 2018;6:301-315. https://doi.org/10.1016/j.tsep.2018.01.017.

[24] Georgiou S, Shah N, Markides CN. A thermo-economic analysis and comparison of pumped-thermal and liquid-air electricity storage systems. Applied Energy 2018;226:1119-1133. https://doi.org/10.1016/i.apenergy.2018.04.128.

[25] Nabat MH, Zeynalian M, Razmi AR, Arabkoohsar A, Soltani M. Energy, exergy, and economic analyses of an innovative energy storage system; liquid air energy storage (LAES) combined with high-temperature thermal energy storage (HTES). Energy Conversion and Management 2020;226. https://doi.org/10.1016/j.enconman.2020.113486.

[26] Georgiou S, Aunedi M, Strbac G, Markides CN. Application of liquid-air and pumped-thermal electricity storage systems in low-carbon electricity systems. In: Heat Powered Cycles - HPC-2018. Bayreuth, Germany; 2018. https://spiral.imperial.ac.uk/handle/10044/1/62577.

[27] Desrues T, Ruer J, Marty P, Fourmigué JF. A thermal energy storage process for large scale electric applications. Applied Thermal Engineering 2010;30(5):425-432. https://doi.org/10.1016/j.applthermaleng.2009.10.002.

[28] Willich C, Markides CN, White AJ. An investigation of heat transfer losses in reciprocating devices. Applied Thermal Engineering 2017;111:903-913. https://doi.org/10.1016/j.applthermaleng.2016.09.136.

[29] White A, McTigue J, Markides C. Wave propagation and thermodynamic losses in packed-bed thermal reservoirs for energy storage. Applied Energy 2014;130:648-657. https://doi.org/10.1016/j.apenergy.2014.02.071.

[30] White AJ. Loss analysis of thermal reservoirs for electrical energy storage schemes. Applied Energy 2011;88(11):4150-4159. https://doi.org/10.1016/i.apenergy.2011.04.030.

[31] White A, Parks G, Markides CN. Thermodynamic analysis of pumped thermal electricity storage. Applied Thermal Engineering 2013;53(2):291-298. http://dx.doi.org/10.1016/j.applthermaleng.2012.03.030.

[32] McTigue JD, White AJ, Markides CN. Parametric studies and optimisation of pumped thermal electricity storage. Applied Energy 2015;137:800-811. http://dx.doi.org/10.1016/j.apenergy.2014.08.039.

[33] McTigue JD, Markides CN, White AJ. Performance response of packed-bed thermal storage to cycle duration perturbations. Journal of Energy Storage 2018;19:379-392. https://doi.org/10.1016/i.est.2018.08.016.

[34] Benato A. Performance and cost evaluation of an innovative pumped thermal electricity storage power system. Energy 2017;138:419-436. http://dx.doi.org/10.1016/j.energy.2017.07.066.

[35] Benato A, Stoppato A. Heat transfer fluid and material selection for an innovative pumped thermal electricity storage system. Energy 2018;147:155-168. https://doi.org/10.1016/j.energy.2018.01.045. 
[36] Benato A, Stoppato A. Energy and cost analysis of a new packed bed pumped thermal electricity storage unit. Journal of Energy Resources Technology 2018;140(2):1-7. http://dx.doi.org/10.1115/1.4038197.

[37] Smallbone A, Jülch V, Wardle R, Roskilly AP. Levelised cost of storage for pumped heat energy storage in comparison with other energy storage technologies. Energy Conversion and Management 2017;152:221228. https://doi.org/10.1016/j.enconman.2017.09.047.

[38] Chen LX, Hu P, Zhao PP, Xie MN, Wang FX. Thermodynamic analysis of a high temperature pumped thermal electricity storage (HT-PTES) integrated with a parallel organic Rankine cycle (ORC). Energy Conversion and Management 2018;177:150-160. http://dx.doi.org/10.1016/i.enconman.2018.09.049.

[39] Georgiou S, Aunedi M, Strbac G, Markides CN. On the value of liquid-air and Pumped-Thermal Electricity Storage systems in low-carbon electricity systems. Energy 2019:1119-1133. https://doi.org/10.1016/i.energy.2019.116680.

[40] Wang L, Lin XP, Chai L, Peng L, Yu D, Liu J, et al. Unbalanced mass flow rate of packed bed thermal energy storage and its influence on the Joule-Brayton based pumped thermal electricity storage. Energy Conversion and Management 2019;185:593-602. https://doi.org/10.1016/i.enconman.2019.02.022.

[41] Wang L, Lin XP, Chai L, Peng L, Yu D, Chen HS. Cyclic transient behavior of the Joule-Brayton based pumped heat electricity storage: Modeling and analysis. Renewable and Sustainable Energy Reviews 2019;111:523-534. https://doi.org/10.1016/j.rser.2019.03.056.

[42] Benoit H, Spreafico L, Gauthier D, Flamant G. Review of heat transfer fluids in tube-receivers used in concentrating solar thermal systems: Properties and heat transfer coefficients. Renewable and Sustainable Energy Reviews 2016;55:298-315. http://dx.doi.org/10.1016/j.rser.2015.10.059.

[43] Vinnemeier P, Wirsum M, Malpiece D, Bove R. Integration of heat pumps into thermal plants for creation of large-scale electricity storage capacities. Applied Energy 2016;184:506-522. http://dx.doi.org/10.1016/j.apenergy.2016.10.045.

[44] Laughlin RB. Pumped thermal grid storage with heat exchange. Journal of Renewable and Sustainable Energy 2017;9(4):044103. https://doi.org/10.1063/1.4994054.

[45] Farres-Antunez P, Xue HB, White AJ. Thermodynamic analysis and optimisation of a combined liquid air and pumped thermal energy storage cycle. Journal of Energy Storage 2018;18:90-102. http://dx.doi.org/10.1016/j.est.2018.04.016.

[46] Farres-Antunez P, McTigue JD, White AJ. A pumped thermal energy storage cycle with capacity for concentrated solar power integration. In: 2019 Offshore Energy and Storage Summit (OSES). BREST, France; 2019. https://doi.org/10.1109/OSES.2019.8867222.

[47] McTigue JD, Farres-Antunez P, Ellingwood K, Neises TW, White AJ. Pumped thermal electricity storage with supercritical $\mathrm{CO}_{2}$ cycles and solar heat input. In: 2019 Solar Power and Chemical Energy Systems Conference. Daegu, South Korea; 2019. https://www.osti.gov/biblio/1570183.

[48] Xue HB. A comparative study of the adiabatic compressed air energy storage (A-CAES) and pumped thermal energy storage (PTES) systems. In: 2019 Offshore Energy and Storage Summit (OSES). BREST, France; 2019. https://ieeexplore.ieee.org/abstract/document/8867354.

[49] Vučković GD, Stojljković MM, Vukić MV, Stefanović GM, Dedeić EM. Advanced exergy analysis and exergoeconomic performance evaluation of thermal processes in an existing industrial plant. Energy Conversion and Management 2014;85:655-662. http://dx.doi.org/10.1016/j.enconman.2014.03.049.

[50] Açıkkalp E, Aras H, Hepbasli A. Advanced exergy analysis of an electricity-generating facility using natural gas. Energy Conversion and Management 2014;82:146-153. http://dx.doi.org/10.1016/i.enconman.2014.03.006.

[51] Wang ZW, Xiong W, Ting DSK, Carriveau R, Wang ZW. Conventional and advanced exergy analyses of an underwater compressed air energy storage system. Applied Energy 2016;180:810-822. http://dx.doi.org/10.1016/j.apenergy.2016.08.014. 
[52] Liu Z, Liu B, Guo J, Xin X, Yang X. Conventional and advanced exergy analysis of a novel transcritical compressed carbon dioxide energy storage system. Energy Conversion and Management 2019;198. http://dx.doi.org/10.1016/i.enconman.2019.111807.

[53] Ebrahimi M, Carriveau R, Ting DSK, McGillis A. Conventional and advanced exergy analysis of a grid connected underwater compressed air energy storage facility. Applied Energy 2019;242:1198-1208. http://dx.doi.org/10.1016/j.apenergy.2019.03.135.

[54] He Q, Liu H, Hao Y, Liu Y, Liu W. Thermodynamic analysis of a novel supercritical compressed carbon dioxide energy storage system through advanced exergy analysis. Renewable Energy 2018;127:835-849. http://dx.doi.org/10.1016/i.renene.2018.05.005.

[55] Mossi Idrissa AK, Goni Boulama K. Advanced exergy analysis of a combined Brayton/Brayton power cycle. Energy 2019;166:724-737. http://dx.doi.org/10.1016/i.energy.2018.10.117.

[56] Galindo J, Ruiz S, Dolz V, Royo-Pascual L. Advanced exergy analysis for a bottoming organic rankine cycle coupled to an internal combustion engine. Energy Conversion and Management 2016;126:217-227. http://dx.doi.org/10.1016/i.enconman.2016.07.080.

[57] Razmi AR, Janbaz M. Exergoeconomic assessment with reliability consideration of a green cogeneration system based on compressed air energy storage (CAES). Energy Conversion and Management 2020;204. https://doi.org/10.1016/j.enconman.2019.112320.

[58] Boyaghchi FA, Molaie $\mathrm{H}$. Sensitivity analysis of exergy destruction in a real combined cycle power plant based on advanced exergy method. Energy Conversion and Management 2015;99:374-386. http://dx.doi.org/10.1016/i.enconman.2015.04.048.

[59] Boyaghchi FA, Molaie $\mathrm{H}$. Investigating the effect of duct burner fuel mass flow rate on exergy destruction of a real combined cycle power plant components based on advanced exergy analysis. Energy Conversion and Management 2015;103:827-835. http://dx.doi.org/10.1016/j.enconman.2015.07.008.

[60] Wang Y, Liu Y, Liu X, Zhang W, Cui P, Yu M, et al. Advanced exergy and exergoeconomic analyses of a cascade absorption heat transformer for the recovery of low grade waste heat. Energy Conversion and Management 2020;205:112392. http://dx.doi.org/10.1016/i.enconman.2019.112392.

[61] Fallah M, Mahmoudi SMS, Yari M, Akbarpour Ghiasi R. Advanced exergy analysis of the Kalina cycle applied for low temperature enhanced geothermal system. Energy Conversion and Management 2016;108:190-201. http://dx.doi.org/10.1016/j.enconman.2015.11.017.

[62] Mohammadi Z, Fallah M, Mahmoudi SMS. Advanced exergy analysis of recompression supercritical $\mathrm{CO}_{2}$ cycle. Energy 2019;178:631-643. http://dx.doi.org/10.1016/i.energy.2019.04.134.

[63] Fallah M, Siyahi H, Ghiasi RA, Mahmoudi SMS, Yari M, Rosen MA. Comparison of different gas turbine cycles and advanced exergy analysis of the most effective. Energy 2016;116:701-715. http://dx.doi.org/10.1016/j.energy.2016.10.009.

[64] Modi A, Pérez-Segarra CD. Thermocline thermal storage systems for concentrated solar power plants: Onedimensional numerical model and comparative analysis. Solar Energy 2014;100:84-93. http://dx.doi.org/10.1016/i.solener.2013.11.033.

[65] Lemmon EW, Huber ML, McLinden MO. NIST Standard Reference Database 23: Reference Fluid Thermodynamic and Transport Properties-REFPROP, Version 9.1 https://www.nist.gov/publications/niststandard-reference-database-23-reference-fluid-thermodynamic-and-transport. [accessed 7 May 2013].

[66] Shah RK, Sekulic DP. Fundamentals of heat exchanger design: John Wiley \& Sons; 2003.

[67] Farres Antunez P, White AJ. Effect of heat capacity variation on high-performance heat exchangers for thermo-mechanical energy storage. In: Offshore Energy and Storage Symposium. Valetta, Malta; 2016. https://www.researchgate.net/publication/339883115.

[68] Xue HB. A comparative analysis and optimisation of thermo-mechanical energy storage technologies [Doctoral dissertation]: University of Cambridge; 2018. 
[69] Nami H, Nemati A, Jabbari Fard F. Conventional and advanced exergy analyses of a geothermal driven dual fluid organic Rankine cycle (ORC). Applied Thermal Engineering 2017;122:59-70. http://dx.doi.org/10.1016/j.applthermaleng.2017.05.011.

[70] Koroglu T, Sogut OS. Conventional and advanced exergy analyses of a marine steam power plant. Energy 2018;163:392-403. http://dx.doi.org/10.1016/j.energy.2018.08.119.

[71] Song J, Li XY, Ren XD, Tian H, Shu GQ, Gu CW, et al. Thermodynamic and economic investigations of transcritical $\mathrm{CO}_{2}$-cycle systems with integrated radial-inflow turbine performance predictions. Applied Thermal Engineering 2019. https://doi.org/10.1016/j.applthermaleng.2019.114604.

[72] Frate GF, Ferrari L, Desideri U. Multi-criteria economic analysis of a pumped thermal electricity storage (PTES) with thermal integration. Frontiers in Energy Research 2020;8:1-19. https://doi.org/10.3389/fenrg.2020.00053.

[73] Salomone-González D, González-Ayala J, Medina A, Roco JMM, Curto-Risso PL, Calvo Hernández A. Pumped heat energy storage with liquid media: Thermodynamic assessment by a Brayton-like model. Energy Conversion and Management 2020;226. https://doi.org/10.1016/..enconman.2020.113540. 